\title{
A Case Study of Anomalous Snowfall with an Alberta Clipper
}

\author{
Scott M. Rochette, ${ }^{1}$ Patrick S. Market, ${ }^{2}$ Chad M. Gravelle, ${ }^{3}$ and Thomas A. Niziol ${ }^{4}$ \\ ${ }^{1}$ Department of the Earth Sciences, The College at Brockport, State University of New York, Brockport, NY, USA \\ ${ }^{2}$ Department of Soil, Environmental and Atmospheric Sciences, University of Missouri, Columbia, MO, USA \\ ${ }^{3}$ NOAA/NWS Operational Proving Ground, Cooperative Institute for Meteorological Satellite Studies, \\ University of Wisconsin-Madison, Kansas City, MO, USA \\ ${ }^{4}$ The Weather Channel, Atlanta, GA, USA \\ Correspondence should be addressed to Scott M. Rochette; rochette@esc.brockport.edu
}

Received 18 May 2017; Revised 9 August 2017; Accepted 17 August 2017; Published 31 October 2017

Academic Editor: Enrico Ferrero

Copyright (C) 2017 Scott M. Rochette et al. This is an open access article distributed under the Creative Commons Attribution License, which permits unrestricted use, distribution, and reproduction in any medium, provided the original work is properly cited.

An Alberta clipper moved over western New York state on 11-12 January 2004, producing snowfall amounts of up to $27 \mathrm{~cm}$ in portions of the region during a roughly 12 -h period. In addition, lightning and thunder were reported. Such systems, known primarily for their fast motion and relatively dry nature, are not generally associated with significant snowfalls. A postmortem analysis of this event, following an ingredients-based methodology, revealed that as the weak low approached the lower Great Lakes, it came under the influence of coupled 300-hPa jets that produced enhanced divergence and significant upward vertical motion over western New York, resulting in the enhanced convective snowfall over the region for a limited time. Instability and possible enhancement via the Great Lakes are also investigated, which show that while there was at least modest instability over the region during the time of heavy snowfall, lake enhancement was unlikely.

\section{Introduction}

The prediction of wintertime precipitation can be challenging, and the consequences of even correct forecasts can be significant. In mid-January 2004 up to $27 \mathrm{~cm}$ (11 in) of snow fell across western New York state, accompanied by thunder and lightning, as an Alberta clipper moved over the region. Such systems are not generally known for producing such intense precipitation, as noted by Bluestein [1] and Thomas and Martin [2], and the vigorous nature of this particular system surprised even seasoned local forecasters who are well acquainted with prolific snowfalls.

The Alberta clipper is generally known to be a fastmoving extratropical cyclone that originates in western Canada and is characterized by low moisture content, defined in Glickman [3]. It is a product of lee cyclogenesis (see Glickman [3]). After formation, clippers typically move toward south-central Canada or the north-central United States, and then toward the east coast of North America (Hutchinson [4]). This track represents one of the major trajectories for cold-season North American cyclones (Petterssen [5]; Reitan [6]; Zishka and Smith [7]; Murray and Simmonds [8]; Hoskins and Hodges [9]; Simmonds and Keay [10]; Ulbrich et al. [11]; Ward [12]). As a result of their fast motions and general lack of available moisture, clipper-type storms typically produce modest precipitation amounts $(7.5-15 \mathrm{~cm}$ in a 3-6 $\mathrm{h}$ period) along a narrow path generally north of the track (Harms [13]; Beckman [14]; Hutchinson [4]; Thomas and Martin [2]). Enhanced snowfall amounts are possible via an influx of Great Lakes moisture (Harms [13]; Cinzani and Changnon Jr. [15]; Silberberg [16]; Angel and Isard [17]) or through the effect of intense upper-level forcing in the presence of reduced static stability (Silberberg [16]; Gallus Jr. and Bresch [18]).

The interaction of transverse circulations associated with two separate upper-level (UL) jet streaks, along with its effects on observed lower- and middle-tropospheric weather features (and their ultimate surface impacts), has been documented in several studies. Uccellini [19] presented four cold-season precipitation episodes over the north-central 
United States during which UL jet coupling occurred, three of which involved relatively weak surface cyclones. He noted that isentropic analysis of the lower troposphere can reveal the atmospheric response to the presence and location of UL jet cores, leading to significant moisture transport and strong upward vertical motion (UVM). Uccellini and Kocin [20] discussed eight cases of US East Coast cyclogenesis during which heavy snow was produced. They noted that the interaction of the direct and indirect thermal circulations associated with two UL jet streaks contributes to favorable differential moisture and temperature advections, along with significant UVM, all of which led to heavy snowfall along the coast. Hakim and Uccellini [21] discussed the role of coupled UL jets in the development of a heavy snow band $(10-20 \mathrm{~cm}$ [4-8 in.]) across the Upper Midwest region of the United States. This band was not associated with major cyclogenesis. They indicated that the forcing mechanism responsible for the heavy snow was the merger of ascent maxima associated with the divergent regions of two juxtaposed UL jet streaks and that the heaviest snow region followed the coupled circulation pattern. Funk and Moore [22] examined a snow band that developed over northern Kentucky in January 1994 and in less than $12 \mathrm{~h}$ resulted in $30-60 \mathrm{~cm}$ (12-24 in.) of snow following a period of freezing rain. Several synoptic- and mesoscale factors conspired to produce this unique episode, including the interaction of two separate UL jet streaks. While coupled upper-level jets are primarily cool-season phenomena, they can occur during the warmer months, as evidenced by a case of flash flooding in July 2006 studied by Kastman et al. [23], in which upper-level jet streak interaction was partly responsible for the elevated convection that led to the excessive precipitation.

The purpose of this paper is to examine the meteorological conditions that led to the anomalous snowfall. Section 2 is a brief description of our data sets and methodology. The event is examined in Section 3. Conclusions and final remarks are offered in Section 4.

\section{Data and Methods}

For this case, analysis of synoptic-scale features was performed using the Eta model (Black [24]; Mesinger et al. [25]), while the Rapid Update Cycle (RUC; Benjamin et al. [26]) model was utilized to examine the UL jet streaks in finer detail, via both plan view and cross-section. The Eta model output was interpolated onto a horizontal grid with $80-\mathrm{km}$ spacing and a 50-hPa vertical spacing, while the RUC model output was interpolated onto a similar grid with 25$\mathrm{hPa}$ vertical intervals. Data were displayed and interrogated using the General Meteorological Package (GEMPAK; Koch et al. [27]). Plan-view analyses were investigated to diagnose the synoptic situation, determine the role of traditional quasi-geostrophic (QG) forcing mechanisms for vertical motion, and track the progress of UL jet streaks across the affected area. Cross-section analyses were created to diagnose ageostrophic circulations, vertical motion fields, and moisture distributions. In addition, backward trajectories were produced by the Hybrid Single Particle Lagrangian Integrated
Trajectory Model (HYSPLIT; Stein et al. [28]) to determine the source regions of air parcels arriving over western New York during the event and to interrogate the potential role of the Great Lakes in the production of heavy snowfall during this episode. North American Regional Reanalysis (NARR; Mesinger et al. [29]) data were used to populate the HYSPLIT model. Radar reflectivity imageries from the US National Weather Service (NWS) Buffalo were included to track snowfall areas and determine their intensities during the storm's passage over western New York and its environs.

As part of the effort to understand how this storm created locally intense snowfall, we have adopted an ingredientsbased methodology (e.g., Doswell III et al. [30]), in which we attempt to identify the contributions of the following features to the overall event:

(i) Synoptic setup

(ii) Mesoscale forcing for ascent

(iii) Moisture

(iv) Potential Great Lakes influences

(v) Instability.

\section{Analysis and Discussion}

3.1. Synoptic Setup. The 1200 UTC 11 January 2004 run of the Eta model was used to illustrate the progression of the synoptic-scale features of this case, which involved a weak Alberta clipper system that was forecast to move from Minnesota to Ontario province over the course of less than $24 \mathrm{~h}$ (Figures $1(\mathrm{a})-1(\mathrm{~d})$ ). The clipper's central pressure was forecast to drop from 1006 to $1005 \mathrm{hPa}$ during its eastward track and then weaken by 1200 UTC 12 January 2004. The 500-hPa height field was equally unimpressive, with a broad trough over the eastern half of North America and an embedded shortwave over the surface cyclone at 1200 UTC 11 January 2004, which subsequently weakened with time. An examination of METAR observations from Buffalo and Niagara Falls (not shown) indicated that light snow had been falling intermittently throughout the early morning of 11 January, with steady snow occurring after 1500 UTC. The Eta model's quantitative precipitation forecast (QPF, not shown) for the Buffalo region during this period was on the order of $12 \mathrm{~mm}(0.5 \mathrm{in})$. Local forecasters were skeptical of this figure, believing it to be overestimated, as revealed in this excerpt from the Warning Forecast Office (WFO) Buffalo area forecast discussion (AFD) issued at 2006 UTC 11 January 2004:

A clipper crosses Lake Ontario late tonight and should bring a general 2 to 4 inches as it passes by. Relatively mild air will hang around during Monday before another short wave pushes a second clipper through late Monday night with a following cold front during Tuesday. The models show the omega field remaining to the north so only chance pops are expected....

As the afternoon and evening progressed, conditions worsened. Here is an excerpt from the 0147 UTC 12 January 2004 WFO Buffalo AFD: 


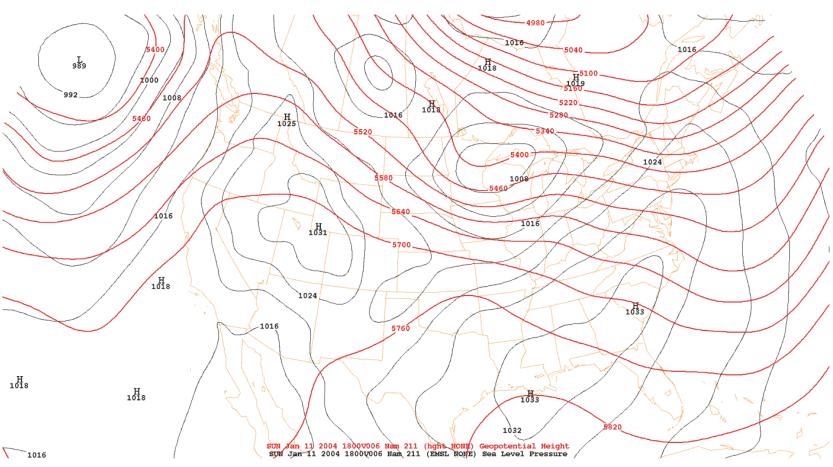

(a) 6-h Eta forecast of mean sea-level pressure (solid black, hPa) and 500-hPa geopotential height (solid red, gpm), valid at 1800 UTC 11 January 2004

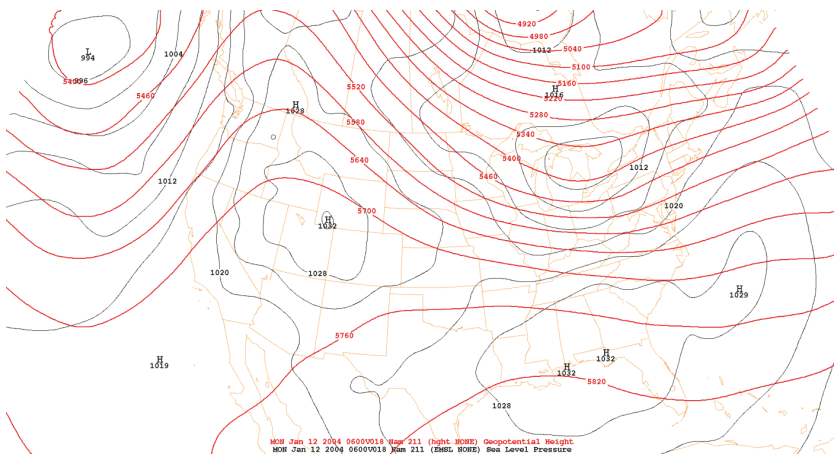

(c) As in Figure 1(a), except 18-h forecast valid at 0600 UTC 12 January 2004

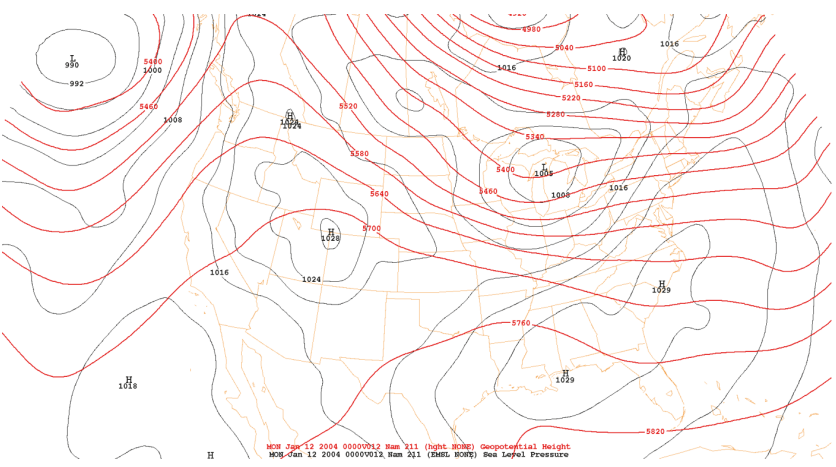

(b) As in Figure 1(a), except 12-h forecast valid at 0000 UTC 12 January 2004

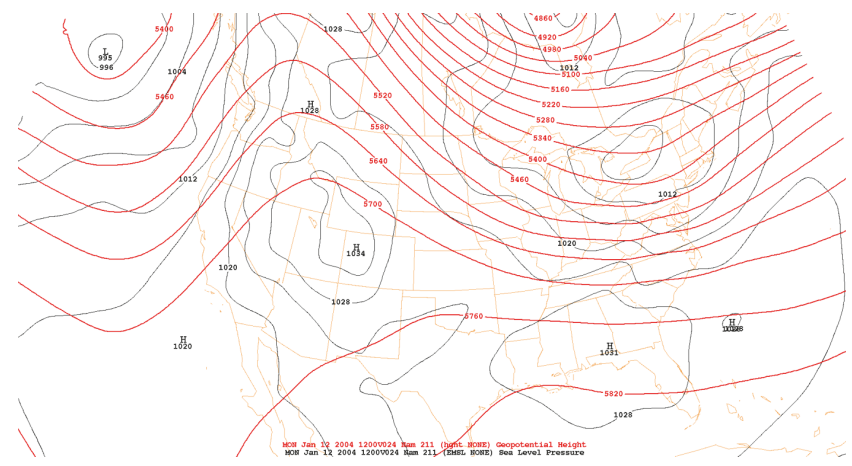

(d) As in Figure 1(a), except 24-h forecast valid at 1200 UTC 12 January 2004

Figure 1

Fast moving clipper moving across the lower Great Lakes places western New York in the area of heaviest snow. Strong boundary layer warm advection ahead of the low is producing bands of heavy snow yielding 1 inch per hour snowfall in portions of the Niagara Frontier with steady but lesser amounts over the Southern Tier and the Genesee Valley to Finger Lakes. Will upgrade to winter storm warning for the Niagara Frontier counties with winter weather advisory elsewhere in western $N Y \ldots$

Local forecasters were not anticipating this system to be exceptional, as Alberta clippers are not generally known to be prolific snowfall producers. Indeed, most stations in the Northeast US and Great Lakes regions reported no more than a few inches of snow on 11 January (Figure 2(a)). Nevertheless, areas of western New York reported up to $27 \mathrm{~cm}$ (11 in) of snow (Figure 2(b)), accompanied by lightning and thunder around 0300 UTC 12 January 2004.

For an event of this type, lift and moisture are certainly anticipated, along with a temperature profile that will support snow. However, this event featured lightning, which merits investigation of static stability.

3.2. Mesoscale Forcing for Ascent. Evaluation of $500-\mathrm{hPa}$ geopotential height and absolute vorticity fields from the Eta model between 1800 UTC 11 January and 1200 UTC 12 January 2004 (Figures 3(a)-3(d)) revealed a shortwave trough that transited from central Minnesota to central Pennsylvania and generally weakened as it did so. A broad area of positive vorticity advection (PVA) was found ahead of the moving trough over the period, entering extreme western New York at 0000 UTC 12 January 2004, and subsequently replaced by negative vorticity advection (NVA) by 1200 UTC. A large region of low-level warm air advection (WAA) was present ahead of the $850-\mathrm{hPa}$ trough through most of the period (Figures 4(a)-4(d)), with neutral to cold air advection (CAA) across western New York at 1200 UTC. We acknowledge that the so-called "traditional" method of evaluating forcing for vertical motion via the individual terms of the quasigeostrophic (QG) omega equation is not ideal (Durran and Snellman [31]; Billingsley [32, 33]). Yet, an examination of mid-tropospheric Q-vectors (not shown) did not indicate significant QG forcing for vertical motion across western New York during the period in question. Meanwhile, the Eta model 500-hPa omega fields indicated a weak, disorganized region of upward motion over and around the upper Great Lakes region east of the surface cyclone at 1800 UTC 11 January 2004 (Figure 5(a)), which became more focused and intense $\left(-10\right.$ to $-12 \mu \mathrm{b} \mathrm{s}^{-1}$ [approximately +15 to $+18 \mathrm{~cm} \mathrm{~s}^{-1}$ ]) over southern Ontario province and western New York state between 0000 and 0600 UTC 12 January 2004 (Figures 5(b)$5(\mathrm{c})$ ), followed by weak forecasted vertical motion by 1200 UTC (Figure 5(d)).

In order to better evaluate the role of upper-level jet streak dynamics in this case, 0 -h RUC model forecasts were 


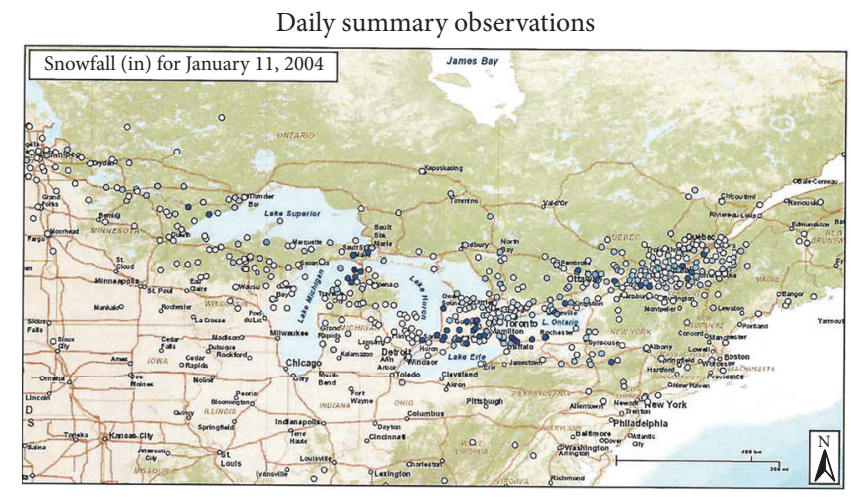

Snowfall (in)
$\circ 0$
○ $2.1-3.0$
○ $5.1-6.0$
○ $3.1-4.0$
- $6.1-7.0$
- $7.1-8.0$
- $8.1-9.0$
- $9.1-10.0$
- $>10.0$

(a) Snowfall amounts (in) for 11 January 2004, courtesy of the National Climatic Data Center

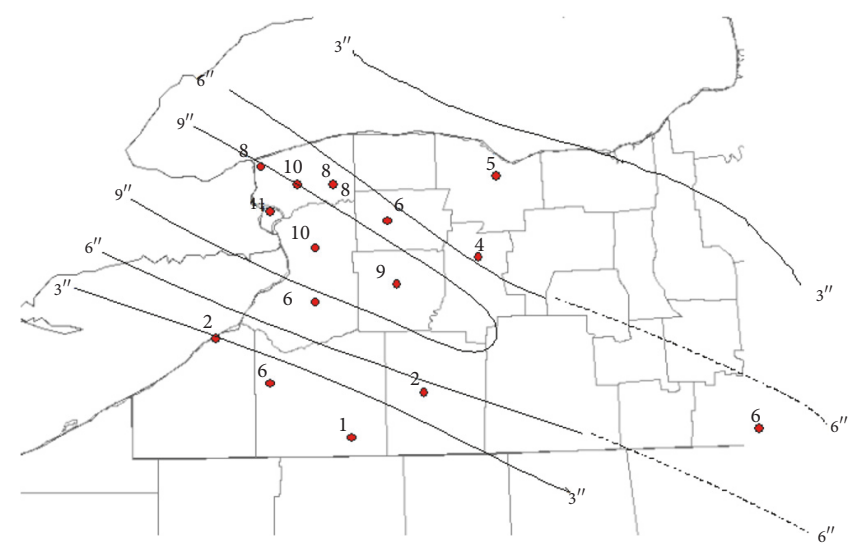

(b) Subjective analysis of 24-h snowfall amounts (in) over western and central New York, ending at 1200 UTC 12 January 2004

FIGURE 2

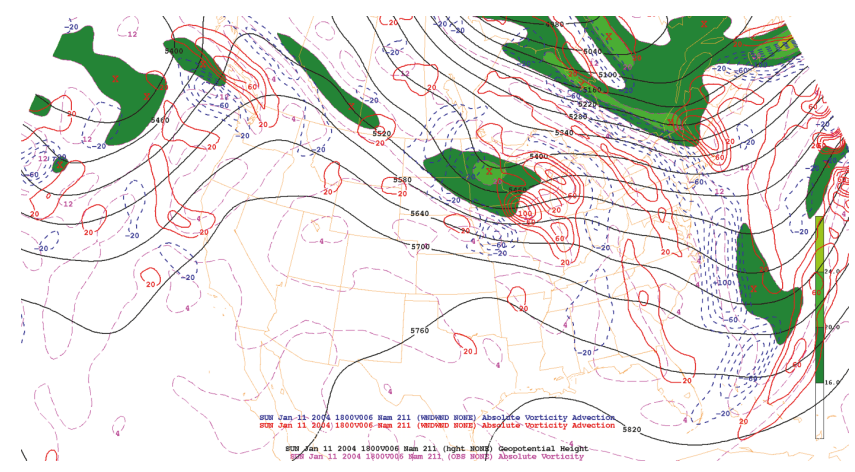

(a) 6-h Eta forecast of 500-hPa geopotential height (solid black, gpm), absolute vorticity (dashed magenta, $10^{-5} \mathrm{~s}^{-1}$; green shading $\geq 16 \times 10^{-5} \mathrm{~s}^{-1}$ ), and absolute vorticity advection (solid red positive, dashed blue negative, $10^{-10} \mathrm{~s}^{-2}$ ), valid at 1800 UTC 11 January 2004

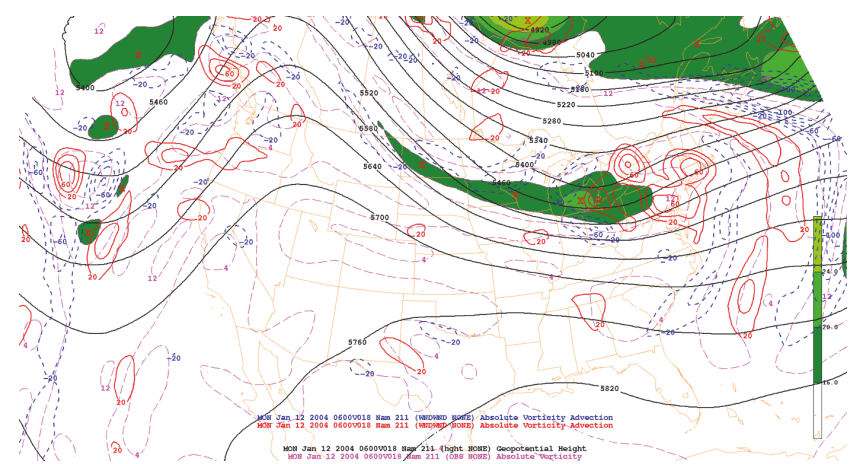

(c) As in Figure 3(a), except 18-h forecast valid at 0600 UTC 12 January 2004

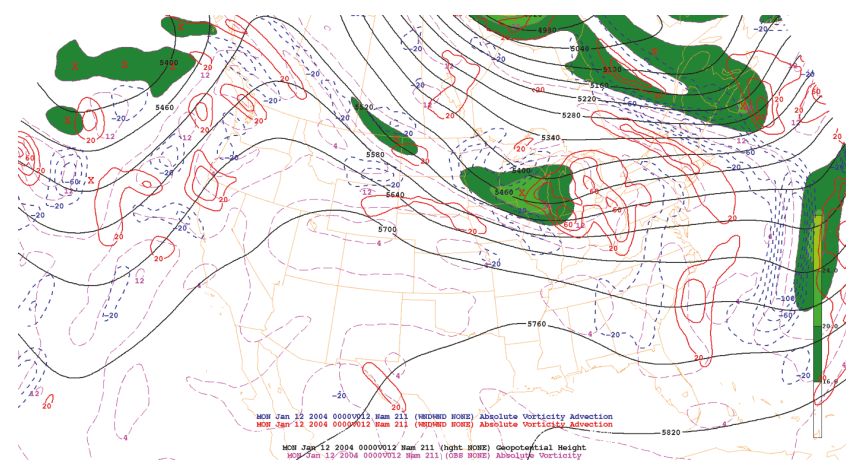

(b) As in Figure 3(a), except 12-h forecast valid at 0000 UTC 12 January 2004

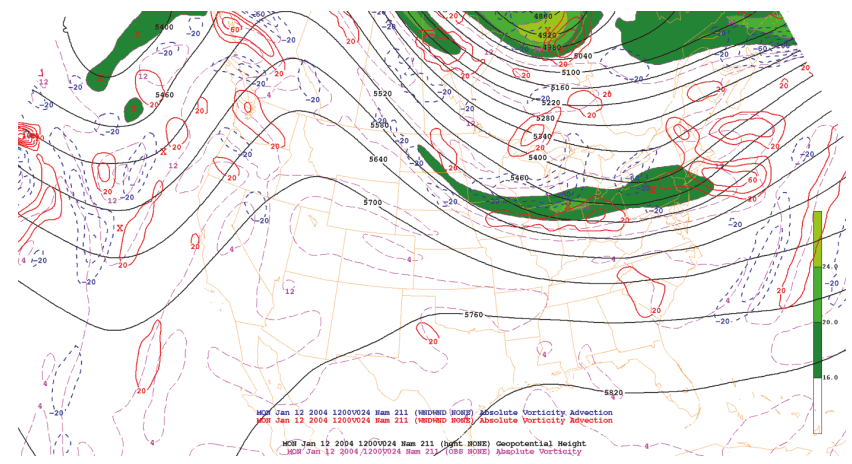

(d) As in Figure 3(a), except 24-h forecast valid at 1200 UTC 12 January 2004

Figure 3 


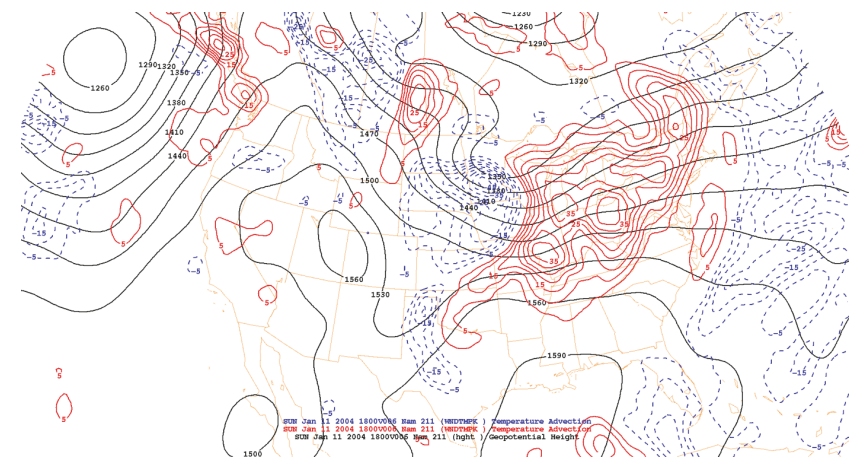

(a) 6-h Eta forecast of 850-hPa geopotential height (solid black, gpm) and temperature advection (solid red positive, dashed blue negative, $10^{-5} \mathrm{~K} \mathrm{~s}^{-1}$ ), valid at 1800 UTC 11 January 2004

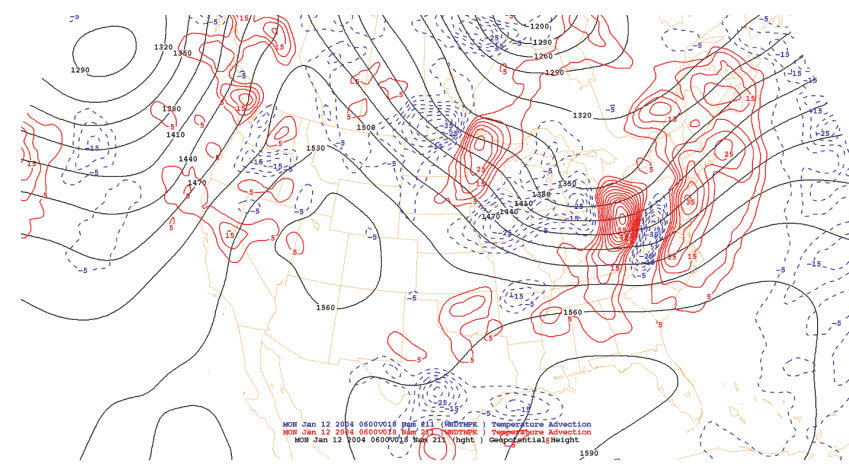

(c) As in Figure 4(a), except 18-h forecast valid at 0600 UTC 12 January 2004

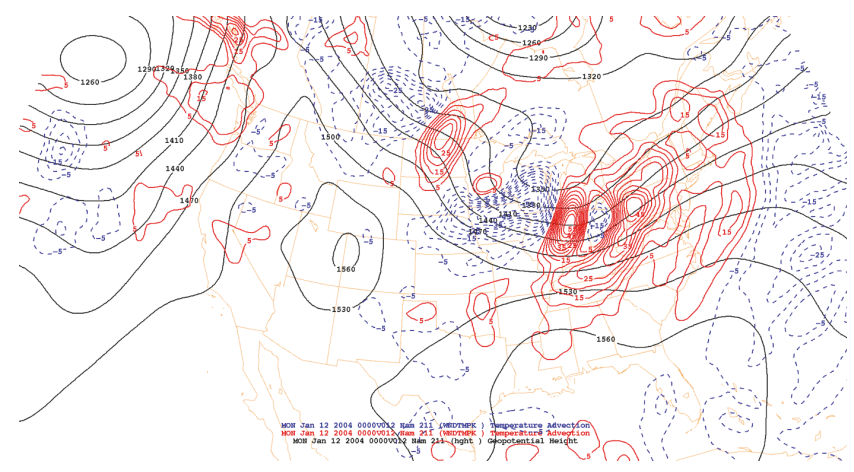

(b) As in Figure 4(a), except 12-h forecast valid at 0000 UTC 12 January 2004

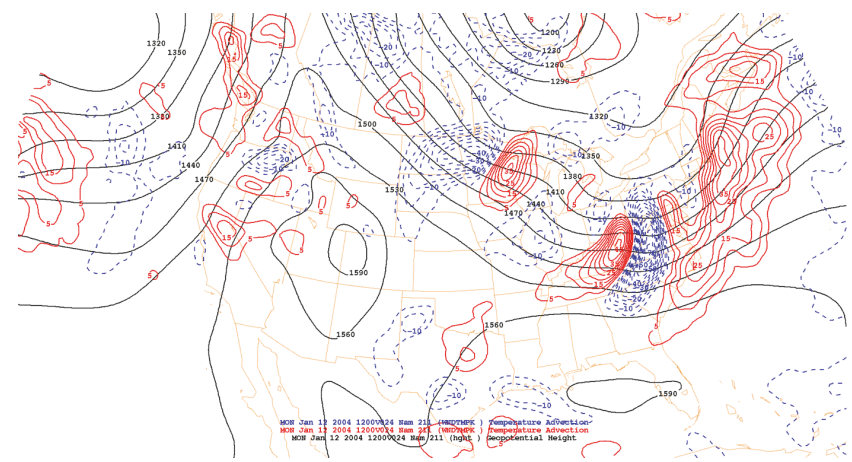

(d) As in Figure 4(a), except 24-h forecast valid at 1200 UTC 12 January 2004

FIGURE 4

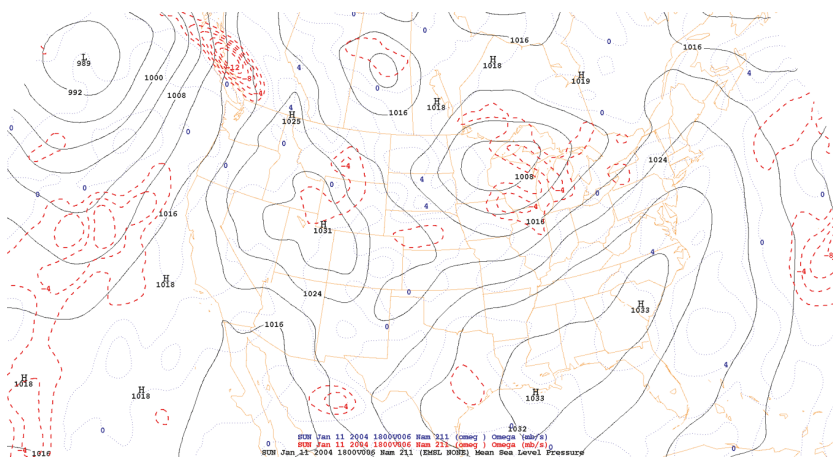

(a) 6-h Eta forecast of mean sea-level pressure (solid black, $\mathrm{hPa}$ ) and 500$\mathrm{hPa}$ omega (dotted blue positive, dashed red negative, $\mu \mathrm{b} \mathrm{s}^{-1}$ ), valid at 1800 UTC 11 January 2004

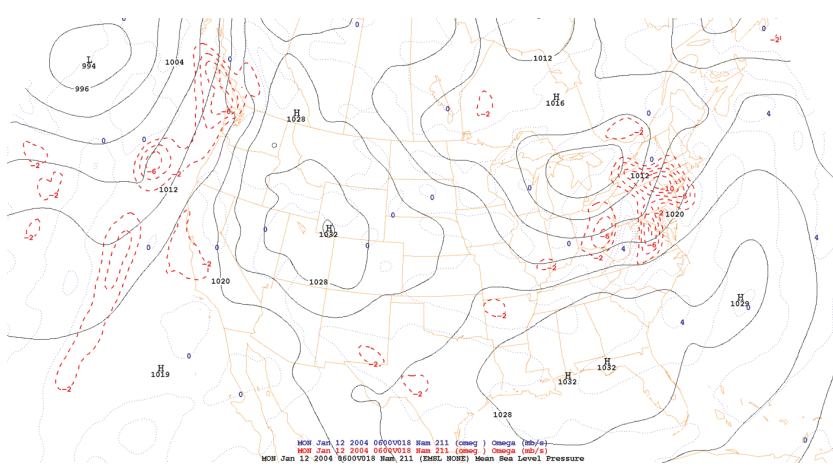

(c) As in Figure 5(a), except 18-h forecast valid at 0600 UTC 12 January 2004

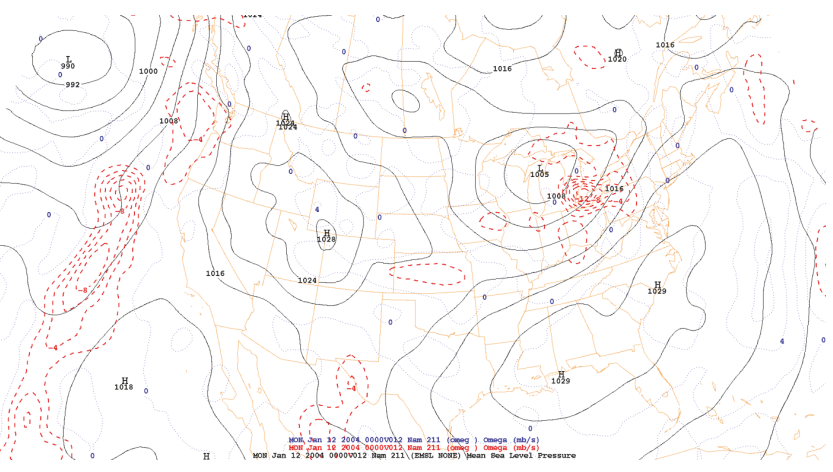

(b) As in Figure 5(a), except 12-h forecast valid at 0000 UTC 12 January 2004

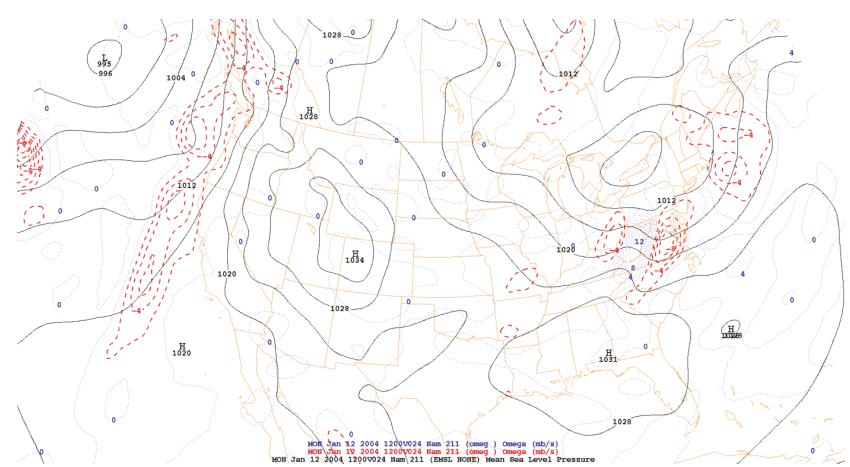

(d) As in Figure 5(a), except 24-h forecast valid at 1200 UTC 12 January 2004 


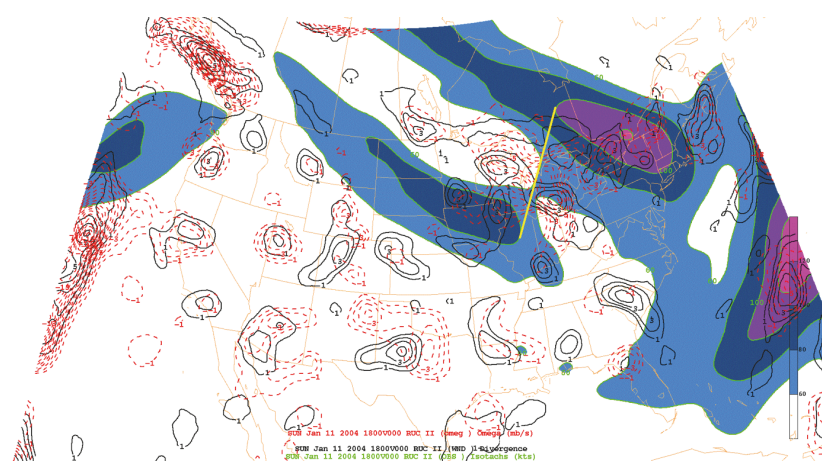

(a) 0 -h RUC forecast of $300-\mathrm{hPa}$ isotachs (solid green/blue shading $\geq$ $30 \mathrm{~m} \mathrm{~s}^{-1}$ [60 kt]), 300-hPa divergence (solid blue, $10^{-5} \mathrm{~s}^{-1}$ ), and $500-\mathrm{hPa}$ omega (dashed red negative, $\mu \mathrm{b} \mathrm{s}^{-1}$ ), valid at 1800 UTC 11 January 2004. Heavy yellow line represents axis of corresponding cross-section analysis shown in Section 3.2

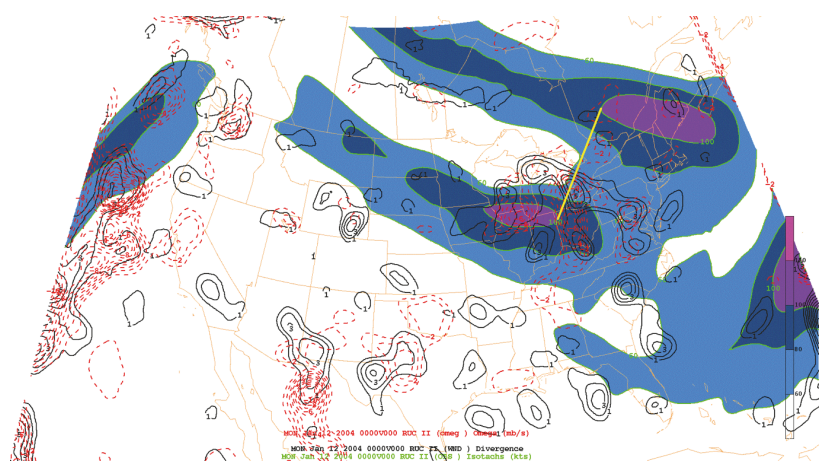

(c) As in Figure 6(a), except valid at 0000 UTC 12 January 2004

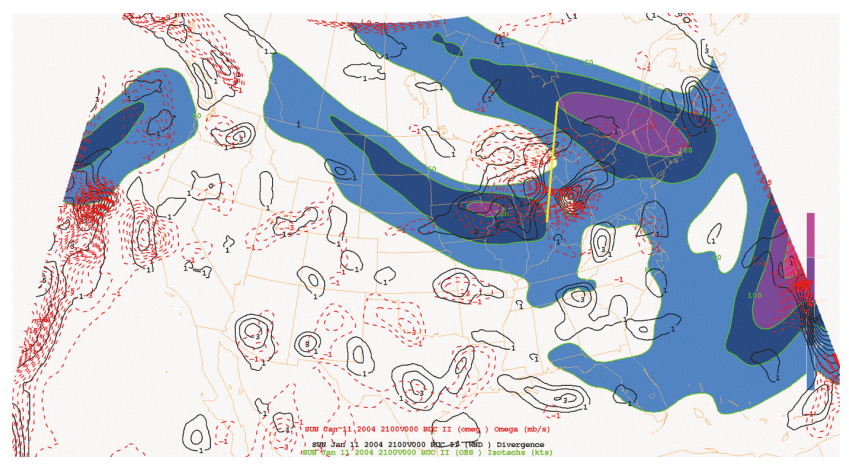

(b) As in Figure 6(a), except valid at 2100 UTC 11 January 2004

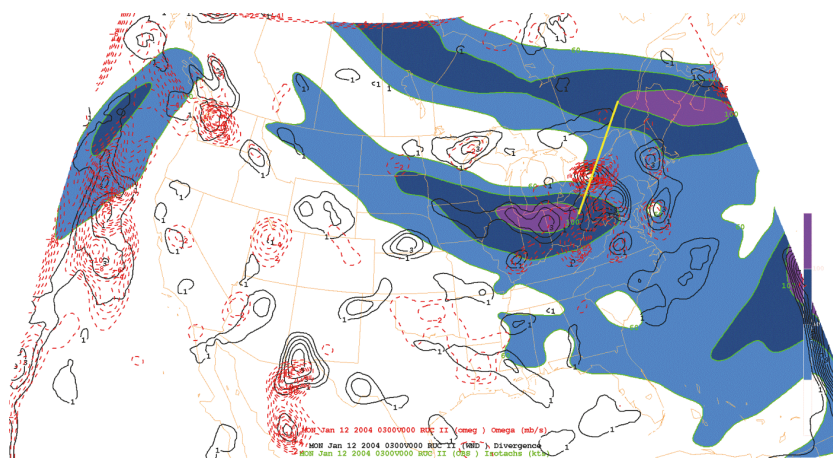

(d) As in Figure 6(a), except valid at 0300 UTC 12 January 2004

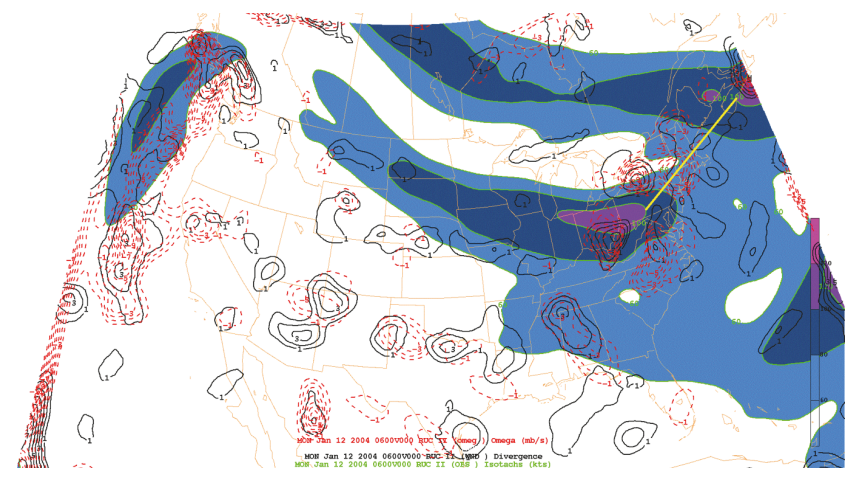

(e) As in Figure 6(a), except valid at 0600 UTC 12 January 2004

Figure 6

examined on a tri-hourly basis, starting at 1800 UTC 11 January 2004. 300-hPa isotach and divergence fields were superposed with $500-\mathrm{hPa}$ omega. The 1800 UTC analysis (Figure 6(a)) showed two distinct jet streaks, the stronger $\left(60 \mathrm{~m} \mathrm{~s}^{-1}[120 \mathrm{kt}]\right.$ maximum) of which was centered just north of the Adirondack region of New York, with a weaker jet (40 $\mathrm{m} \mathrm{s}^{-1}$ [80 kt] maximum) to its southwest over the Upper Mississippi Valley and Northern Plains. This jet streak pattern is similar to that found in a study of coupled jet streaks associated with weak surface cyclones (Rochette et al. [34]). There was a broad region of divergence linking the right entrance and left exit regions of the two jets, which coincided well with a region of rising motion from the Minnesota Arrowhead southeastward into Lower Michigan, Ohio, and the lower Great Lakes region.

The 2100 UTC analysis (Figure 6(b)) indicates the first signal of jet streak interaction. Each jet has propagated eastward slightly, with the southern jet showing modest strengthening in the form of a $50 \mathrm{~m} \mathrm{~s}^{-1}$ (100 kt) maximum over northeastern Iowa. The northern jet weakened slightly, with maximum winds in the $50 \mathrm{~m} \mathrm{~s}^{-1}$ (100 kt) range. The divergence and omega signals are more distinct and focused than at 1800 UTC, with the strongest rising motion $\left(-16 \mu \mathrm{b} \mathrm{s}^{-1}\left[+24 \mathrm{~cm} \mathrm{~s}^{-1}\right]\right)$ over the western end of Lake Erie. 
The two jets continued their eastward progress at 0000 UTC 12 January 2004 (Figure 6(c)), with a broad but still distinct coupling signal over the Great Lakes. 500-hPa vertical motion had weakened slightly but still showed a relative minimum omega of $-6 \mu \mathrm{b} \mathrm{s}^{-1}\left(+9 \mathrm{~cm} \mathrm{~s}^{-1}\right)$ over southern Lake Huron. Midlevel frontogenesis was examined during this period (not shown), revealing a modest NW-SE band across the Niagara Peninsula, quite likely attributable to latent heat release via the strong ascent due to the jet interaction.

At 0300 UTC 12 January 2004 (Figure 6(d)), the jets propagated eastward while maintaining their strengths. The coupled jet signal followed a similar path over western New York. The southern jet's left exit region covered western New York and northwestern Pennsylvania at this time, while the right entrance region of the northern jet passed over the St. Lawrence River Valley of Quebec. The divergence and omega fields $\left(-16 \mu \mathrm{b} \mathrm{s}^{-1}\left[+24 \mathrm{~cm} \mathrm{~s}^{-1}\right]\right)$ had significant maxima over the Niagara Peninsula of southern Ontario province. It was at this time that the snowband was at its most vigorous. Finally, the 0600 UTC analysis (Figure 6(e)) has the northern jet streak pulling off the coast of Nova Scotia, while the southern jet pushed eastward into central Pennsylvania, placing a well-focused divergent region over western and central New York state, along with a nearly collocated omega minimum $\left(-8 \mu \mathrm{b} \mathrm{s}^{-1}\left[+12 \mathrm{~cm} \mathrm{~s}^{-1}\right]\right)$. By this time, the precipitation shield was becoming less organized across western New York.

The RUC initial fields were used to create cross-sections matching the times of the jet streak analyses detailed in the preceding section. The cross-section axes were drawn from the western edge of the strongest isotach of the northern jet streak to the eastern edge of the southern jet streak and are highlighted on the jet streak analyses shown previously. Siting of the cross-section axes was attempted to capture the coupled region between the two upper-level jet streaks.

The 1800 UTC 11 January 2004 cross-section (Figure 7(a)) highlights the presence of two jet streaks, the stronger one to the north of the slightly weaker one. A broad area of moist air can be found underneath the coupled region, extending upward through the mid-troposphere. Embedded in this region was an area of UVM, with a midlevel maximum close to the center of the coupled region. Three hours later (Figure 7(b)), the moist layer had expanded horizontally beneath the coupled region, with two distinct midlevel UVM maxima corresponding to the divergent regions of the two jets, the southern maximum being significantly stronger $\left(-10 \mu \mathrm{b} \mathrm{s}^{-1}\right.$ [approximately $+15 \mathrm{~cm} \mathrm{~s}^{-1}$ ]) than the northern maximum $\left(-4 \mu \mathrm{b} \mathrm{s}^{-1}\left[+6 \mathrm{~cm} \mathrm{~s}^{-1}\right]\right)$.

The 0000 UTC 12 January 2004 cross-sectional analysis (Figure 7(c)) reveals a region of nearly saturated air sloping from underneath the exit region of the southern jet upward and northward toward the entrance region of the northern jet. Two UVM maxima were present once again $\left(\sim-6 \mu \mathrm{b} \mathrm{s} \mathrm{s}^{-1}\right.$ $\left.\left[+9 \mathrm{~cm} \mathrm{~s}^{-1}\right]\right)$ : a near-surface region under the exit region of the southern jet and another located near $700 \mathrm{hPa}$ in the coupled region, located in the $90 \%$ relative humidity swath. Three hours later (Figure 7(d)), the strongest signal for jet coupling and its consequences were found. A broad area of $\mathrm{RH} \geq 70 \%$ was present from the surface through the mid-troposphere underneath the coupled region, characterized by strongly divergent ageostrophic wind vectors in the upper troposphere. Incredibly strong midlevel UVM was present underneath the coupling region, with omega values of $-16 \mu \mathrm{b} \mathrm{s}^{-1}$ (approximately $+24 \mathrm{~cm} \mathrm{~s}^{-1}$ ). The 0600 UTC cross-section (Figure $7(\mathrm{e})$ ) shows drier air starting to work into the northern half of the cross-section at low levels. The signal of the southern jet was not nearly as distinct (although still present, as evidenced in Figure 6(e)), while the UVM maximum $\left(-7 \mu \mathrm{b} \mathrm{s}^{-1}\left[+11 \mathrm{~cm} \mathrm{~s}^{-1}\right]\right)$ was weaker than at 0300 UTC but extended through a deeper layer of the troposphere.

3.3. Moisture. Anomalous precipitation in this system suggests the possibility of above normal moisture available for snow creation. As a means to assess both moisture abundance and origin, 72-hour backward trajectory ensembles were created using HYSPLIT, using three-hourly NARR fields as input data. The 27 ensemble trajectories were created by shifting the meteorology grid by one grid point in each of the horizontal directions and 0.01 sigma units in the vertical. In this section, we examined four different levels, terminating close to the surface (Figure 8(a)), as well as terminating near traditional meteorological levels, such as $1500 \mathrm{~m}$ above ground level (AGL; Figure 8(b)), 3000 m AGL (Figure 8(c)), and $5400 \mathrm{~m}$ AGL (Figure 8(d)); these latter three values approximate $850 \mathrm{hPa}, 700 \mathrm{hPa}$, and $500 \mathrm{hPa}$, respectively. The end time for all trajectories was 0300 UTC 12 January 2004, near the time of heaviest snow.

The lowest level trajectory (Figure 8(a)) reveals parcels that have spent the previous 72 hours almost entirely over a continental surface, with an initial northerly flow becoming southerly in the latter portion of most paths. The 24-72-hour time frame is dominated by parcel relative humidity values of $50-60 \%$, even though many descended from above $500 \mathrm{~m}$ AGL (not shown) in that period. Parcel relative humidity values increased with time over the last 24 hours of their path, while most of the paths hovered between 0 and $250 \mathrm{~m}$ AGL. Thus cooling and/or moistening of parcels occurred in the last 24 hours, though adiabatic ascent was not the cause here. Even so, near-surface relative humidity values average a clearly unsaturated 87\% at 0300 UTC 12 January 2004.

For parcels terminating at $1500 \mathrm{~m}$ AGL (Figure 8(b)), a similar horizontal life history is depicted, with a northerly flow again turning southerly, though that change comes $\sim 48$ hours prior to termination at $1500 \mathrm{~m}$, as opposed to $\sim 24$ hours prior to termination at $250 \mathrm{~m}$. Relative humidity values gradually dropped for most parcel paths, from $\sim 80 \%$ at 0300 UTC 09 January 2004 ( $72 \mathrm{~h}$ out) to $\sim 60 \%$ at 0300 UTC 11 January 2004 (24 h out). Meanwhile, most parcel trajectories show very little vertical motion and spend most of their path at or below $500 \mathrm{~m} \mathrm{AGL}$ (not shown). In the last 12 hours of the trajectory swarm, most of the parcels ascended $\sim 1000 \mathrm{~m}$ $\left(\sim 2 \mathrm{~cm} \mathrm{~s}^{-1}\right)$, and mean relative humidity values escalated rapidly to $91 \%$ by trajectory termination.

The parcel swarm terminating at $3000 \mathrm{~m}$ AGL (Figure 8(c)) reveals a different life history, paths of more transient flow that span the North American continent over their 72 hours. Most trajectories clearly encountered 


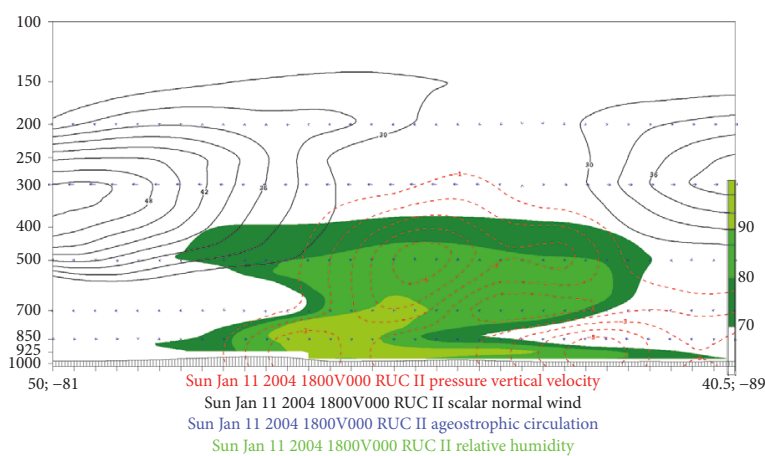

(a) 0-h RUC forecast cross-section of normal isotachs (solid black $\geq 30 \mathrm{~m} \mathrm{~s}^{-1}$ [60 kt]), relative humidity (green shading $\geq 70 \%$ ), omega (dashed red negative, $\mu \mathrm{b} \mathrm{s}^{-1}$ ), and ageostrophic circulation (blue vectors), valid at 1800 UTC 11 January 2004

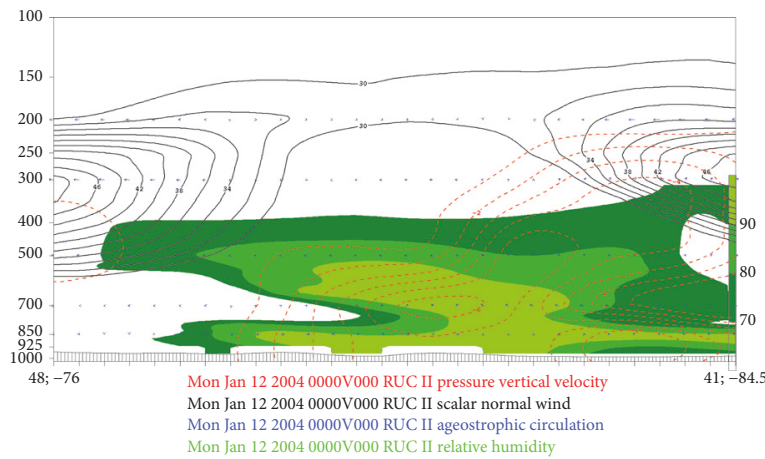

(c) As in Figure 7(a), except valid at 0000 UTC 12 January 2004

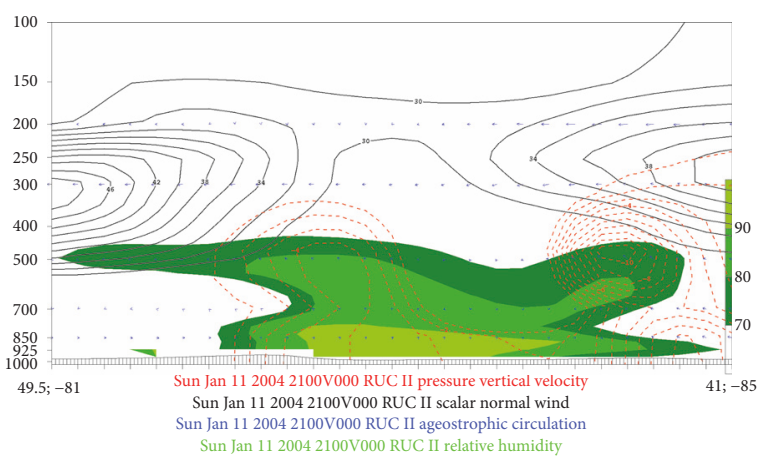

(b) As in Figure 7(a), except valid at 2100 UTC 11 January 2004

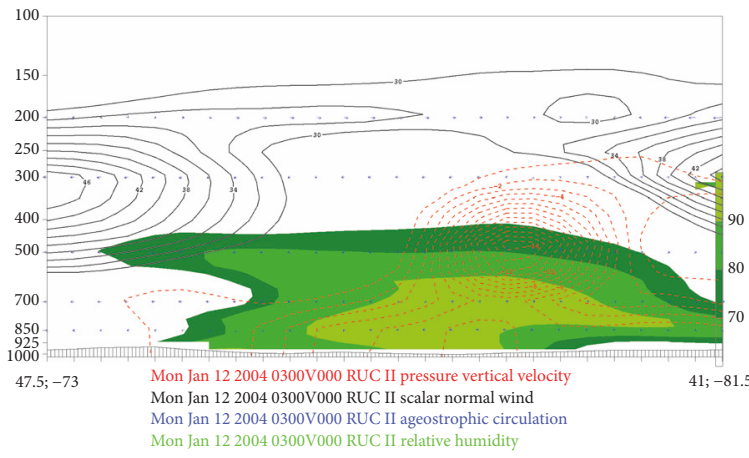

(d) As in Figure 7(a), except valid at 0300 UTC 12 January 2004

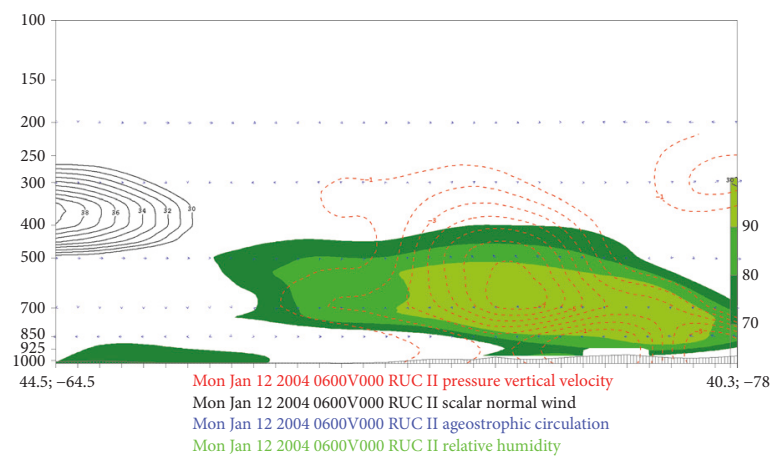

(e) As in Figure 7(a), except valid at 0600 UTC 12 January 2004

Figure 7

cyclonic flow in the lee of the Rockies. A typical life history of descent is also calculated until 1200 UTC 11 January 2004, when the typical parcel resided at $\sim 1200 \mathrm{~m}$ AGL. The last 15 hours reveals a typical vertical change of $1800 \mathrm{~m}$ $\left(\sim 3 \mathrm{~cm} \mathrm{~s}^{-1}\right)$, while the relative humidity values climb from $\sim 35 \%$ to $88 \%$.

The final parcel swarm examined terminated at $5400 \mathrm{~m}$ AGL (Figure 8(d)). Most of these parcels also spent much of their time over the North American continent, though they all do originate over the Pacific. All paths in this backward parcel swarm began off the California coast, at $\sim 30^{\circ} \mathrm{N}$, at a typical elevation of $2500 \mathrm{~m}$ AGL. Not surprisingly, the last 18 hours in these paths also reveals a significant increase in elevation, typically $3000 \mathrm{~m}\left(\sim 4.5 \mathrm{~cm} \mathrm{~s}^{-1}\right)$. Relative humidity values again increased in the last day or so before termination but dropped off slightly in the last 6 hours to $73 \%$.

These trajectory swarms show, both individually and collectively, that this was not a storm having an overabundance of water vapor with which to create anomalous snowfall. True, these values evince the moisture available to a typical wintertime storm, but the trajectories do not originate over regions with abundant moisture, nor do the parcels have much of a life history of near saturation. Given that the relative humidity is a temperature dependent variable, we also offer as additional evidence the precipitable water $(12.3 \mathrm{~mm})$ from the 0000 UTC 12 January 2004 sounding from Buffalo, 


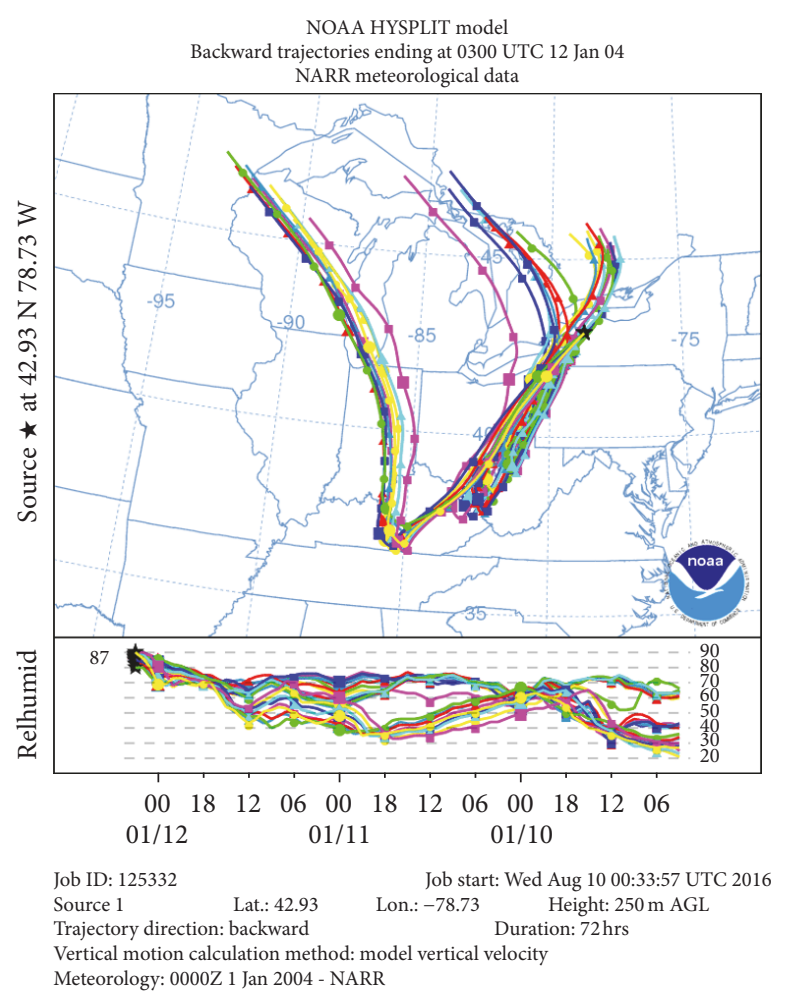

(a) Plot of an ensemble of 27,72-hour HYSPLIT backward trajectories from $250 \mathrm{~m}$ above ground level (AGL) at Buffalo, New York (denoted by the star), at 0300 UTC 12 January 2004, based upon 3-hourly NARR input. Each path is presented in a different color, with a marker every 6 hours on its path. Top (plan view) plot depicts parcel paths, while bottom is a hygrograph depicting how the relative humidity (\%; ordinate) varies in time (every 6 hours; abscissa) for each trajectory

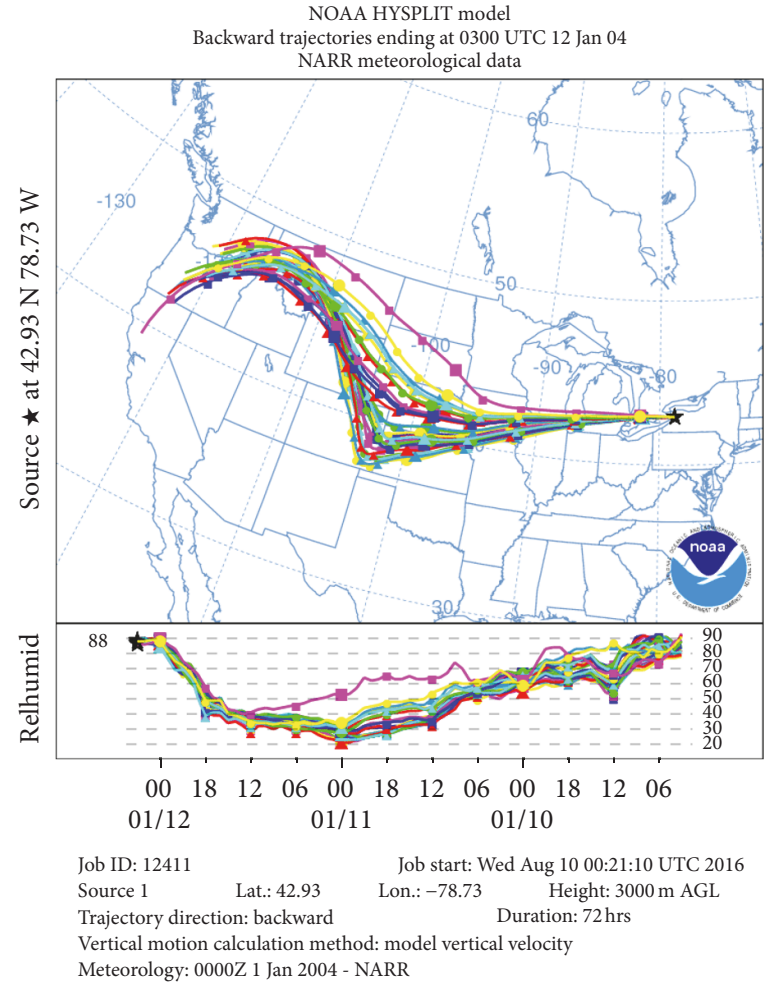

(c) As in Figure 8(a), except for $3000 \mathrm{~m}$ AGL

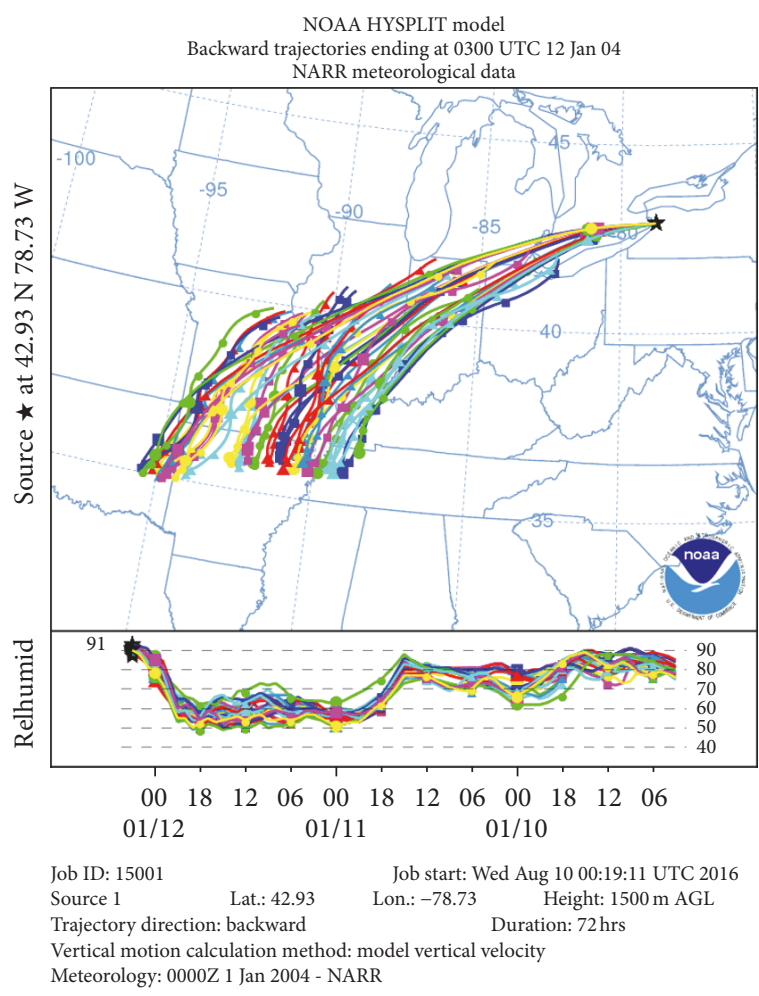

(b) As in Figure 8(a), except for $1500 \mathrm{~m}$ AGL

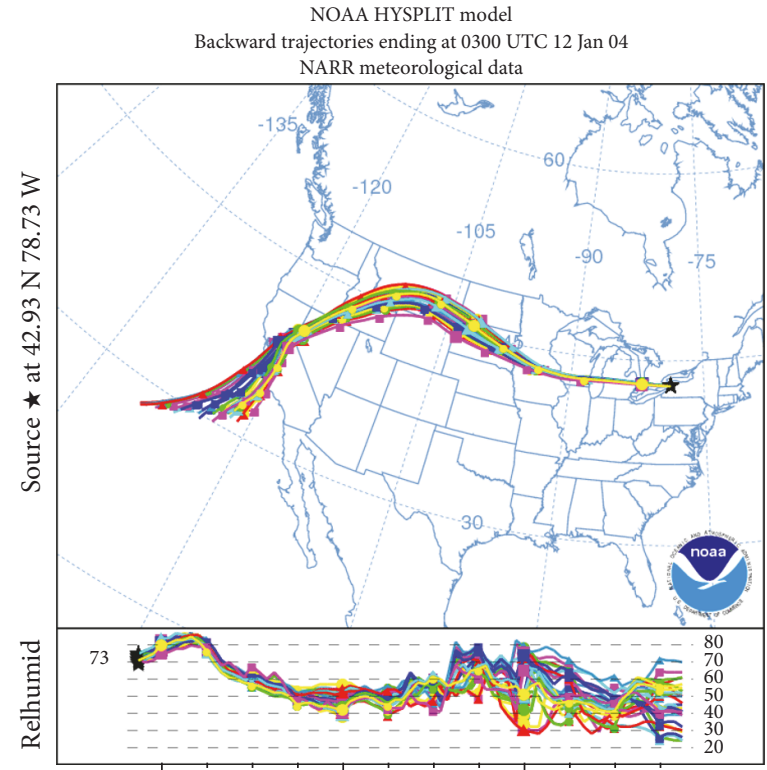

$\begin{array}{lllllllllllll}00 & 18 & 12 & 06 & 00 & 18 & 12 & 06 & 00 & 18 & 12 & 06\end{array}$

$$
01 / 12 \quad 01 / 11 \quad 01 / 10
$$

Job ID: 17888 Job start: Wed Aug 10 00:22:48 UTC 2016 Source 1 Lat.: 42.93 Lon.: -78.73 Height: $5400 \mathrm{~m} \mathrm{AGL}$ Trajectory direction: backward Duration: $72 \mathrm{hrs}$

Vertical motion calculation method: model vertical velocity

Meteorology: 0000Z 1 Jan 2004 - NARR

(d) As in Figure 8(a), except for 5400 m AGL 


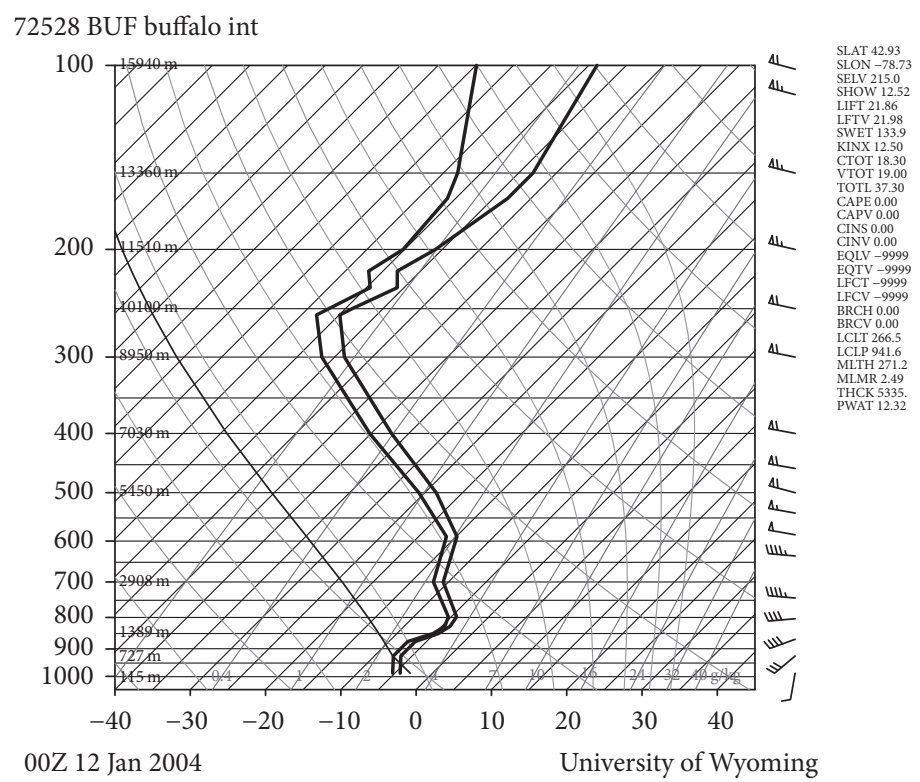

Figure 9: Skew- $T \log p$ thermodynamic diagram of temperature (solid right, ${ }^{\circ} \mathrm{C}$ ) and dew point (solid left, ${ }^{\circ} \mathrm{C}$ ), based on radiosonde observations from Buffalo, NY (KBUF), valid at 0000 UTC 12 January 2004 . Wind barbs are in standard plotting convention (flag $=25 \mathrm{~m} \mathrm{~s}^{-1}$, full feather $=5 \mathrm{~m} \mathrm{~s}^{-1}$, half feather $=2.5 \mathrm{~m} \mathrm{~s}^{-1}$ ). Diagram courtesy of University of Wyoming.

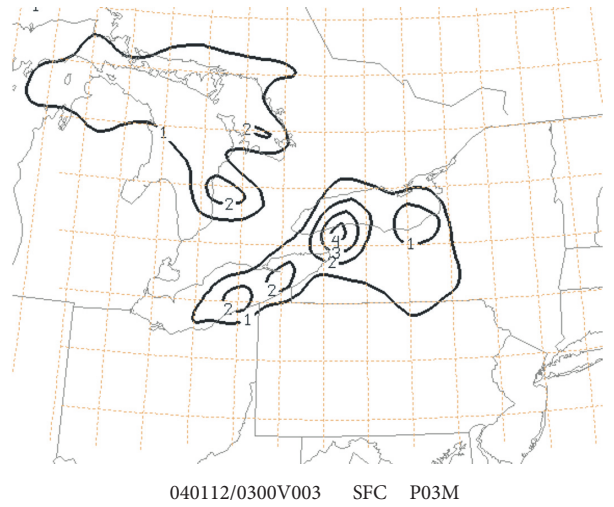

FIGURE 10: 3-hour accumulated liquid precipitation (solid, mm) in the NARR for the period ending at 0300 UTC 12 January 2004.

NY (Figure 9). This value falls within the first standard deviation and is approximately half of the all-time maximum for that date in Buffalo (NOAA [35]).

We close the trajectory analysis by noting that the last 12-24 hours of each trajectory swarm, when viewed together, reveals a veering wind profile. This signature corroborates the idea of deep warm advection as a forcing mechanism for ascent. Yet, the previous analyses, as well as the trajectories themselves, suggest modest synoptic-scale ascent values. This idea, coupled with typical atmospheric moisture values, would tend to suggest a less significant storm, with accumulations of the expected 8 to $15 \mathrm{~cm}$ range (e.g., Thomas and Martin [2]). Thus we turn to analyses of lake influence and static stability to determine a possible means of enhanced mesoscale upward motion in this system.
3.4. Potential Great Lakes Influences. The snowband's location invokes the possibility of lake enhancement of the precipitation. The NARR 3-hour precipitation (Figure 10) matches well with the previous snowfall maps (see Figures 2(a)$2(b))$. There is some question of lake-enhanced precipitation. Within the NARR, a precipitation band aligned along and parallel to the southern shore of Lake Erie. There, maximum 3-hour values of $2.5 \mathrm{~mm}$ were generated, ending at $0300 \mathrm{UTC}$ 12 January 2004. Yet it is clear that the bulk of the NARR precipitation accumulation is transient, borne of larger-scale forcing. To underscore this point, the NARR sensible heat flux (Figure 11) and latent heat flux (Figure 12) at 0000 UTC 12 January 2004 match well with typical January values in the region (NOAA [36]). Significant lake contributions were unlikely. 


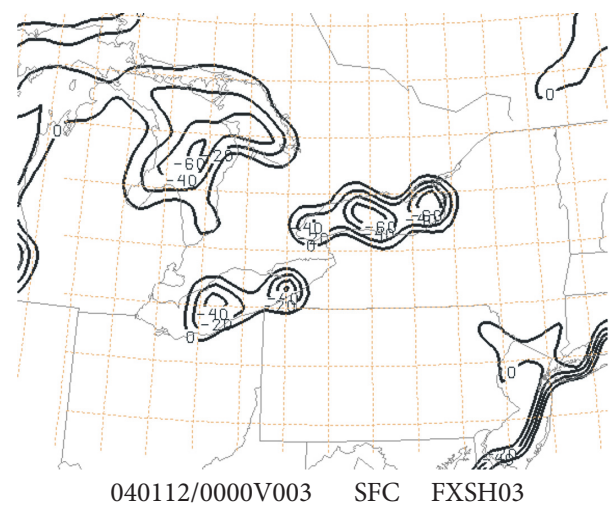

FIgURE 11: Sensible heat flux (solid, $\mathrm{W} \mathrm{m}^{-2}$ ) in the NARR at 0300 UTC 12 January 2004.

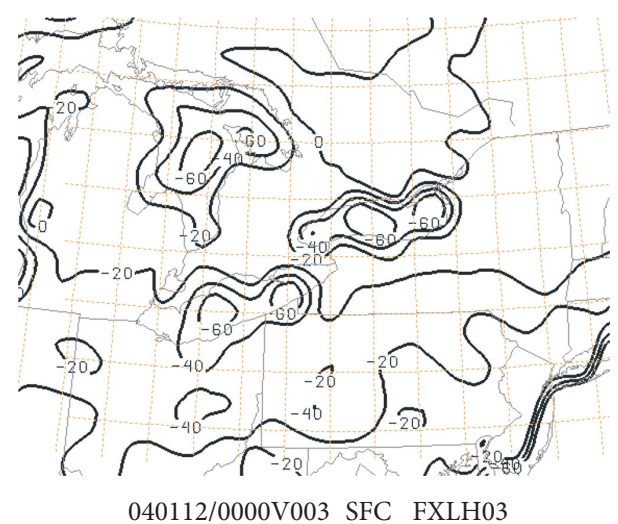

FIGURE 12: Latent heat flux (solid, $\mathrm{W} \mathrm{m}^{-2}$ ) in the NARR at 0300 UTC 12 January 2004.

3.5. Instability. In the absence of significant lake surface influences and in the presence of fairly typical moisture profiles, we look to the thermodynamic profiles to assess instability as a mechanism for generating anomalously large snowfall totals. We will look first at the NARR soundings in the 0000 UTC to 0600 UTC 12 January 2004 time frame. Being constructed with its $4 \mathrm{D}$ assimilation method, the NARR reanalyses retain continuity with the preceding analyses in this study.

Of the times examined, the 0600 UTC 12 January 2004 NARR sounding for Buffalo, New York, (Figure 13(a)) was the least statically stable of the group. The NARR soundings for Buffalo immediately prior (0000 UTC and 0300 UTC, not shown) are less impressive, having lifting parcel levels of $650 \mathrm{hPa}$ (both), Lifted Index values (Lifted Index is the algebraic difference between the temperature of a adiabatically lifted parcel (based on a near-surface mixed layer) and that of the environment at $500 \mathrm{hPa}$; positive values indicate a parcel that is cooler than the environment, indicating static stability) of +4 (0000 UTC) and +2 (0300 UTC), and $700-500-\mathrm{hPa}$ lapse rates of $5.7 \mathrm{~K} \mathrm{~km}^{-1}$ (0000 UTC) and $6.4 \mathrm{~K} \mathrm{~km}^{-1}$ (0300 UTC). However the 0600 UTC sounding is quite similar to the model suggested by Market et al. [37]

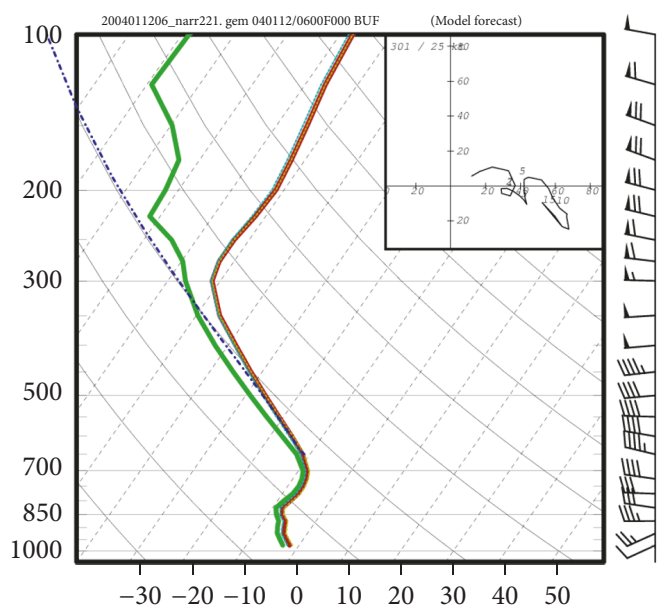

(a) Skew- $T \log p$ thermodynamic diagram of temperature (solid red, ${ }^{\circ} \mathrm{C}$ ) and dew point (solid green, ${ }^{\circ} \mathrm{C}$ ) for Buffalo, New York, at 0600 UTC 12 January 2004 from the NARR. Wind barbs follow as in Figure 9

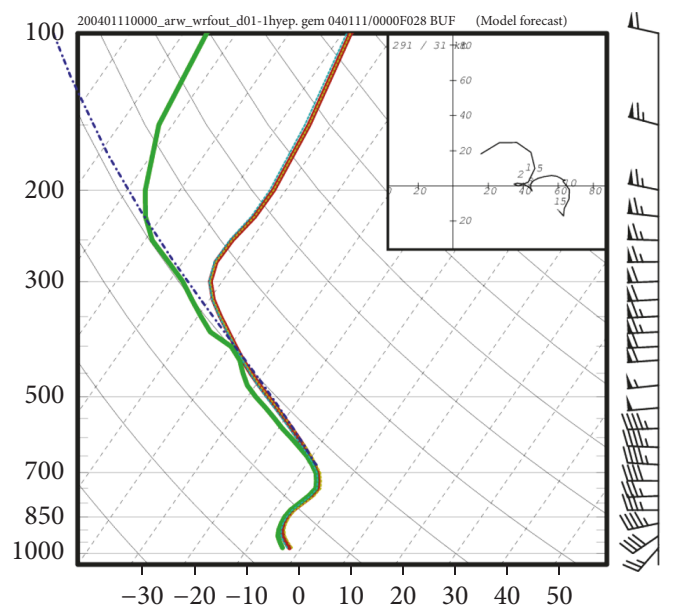

(b) As in Figure 13(a), except at 0400 UTC 12 January 2004 from an experimental, 13-km, hydrostatic WRF simulation

FIGURE 13

for midwestern United States convective snow cases, with a Lifted Index of 0 , and a 700-500-hPa lapse rate of $7.2 \mathrm{~K} \mathrm{~km}^{-1}$. However, no most unstable convective available potential energy (MUCAPE) is diagnosed at any of these times.

It is worth noting that an experimental run with the Weather Research and Forecasting (WRF; Skamarock and Klemp [38]) model for this event produced a sounding profile (Figure 13(b)) for Buffalo at 28 hours (0400 UTC 12 January 2004) that was quite similar to the NARR output at 0600 UTC (Figure 13(a)). This 13-km hydrostatic solution identified $46 \mathrm{~J} \mathrm{~kg}^{-1}$ of MUCAPE for a parcel lifted from $675 \mathrm{hPa}$. All of the soundings shown herein point to an atmosphere conducive to lightning, which was observed. Thus the release of midlevel potential instability occurred to aid in both lightning generation and snow production.

3.6. Radar. The 1758 UTC 11 January $20040.5^{\circ}$ elevation radar reflectivity image from the Buffalo NWS (Figure 14(a)) 


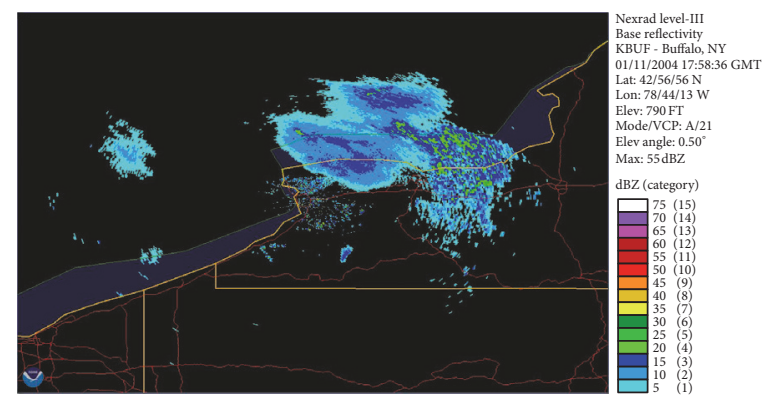

(a) National Weather Service Forecast Office Buffalo (KBUF) $0.5^{\circ}$ elevation radar reflectivity (dBZ), valid at 1758 UTC 11 January 2004, courtesy of the National Climatic Data Center

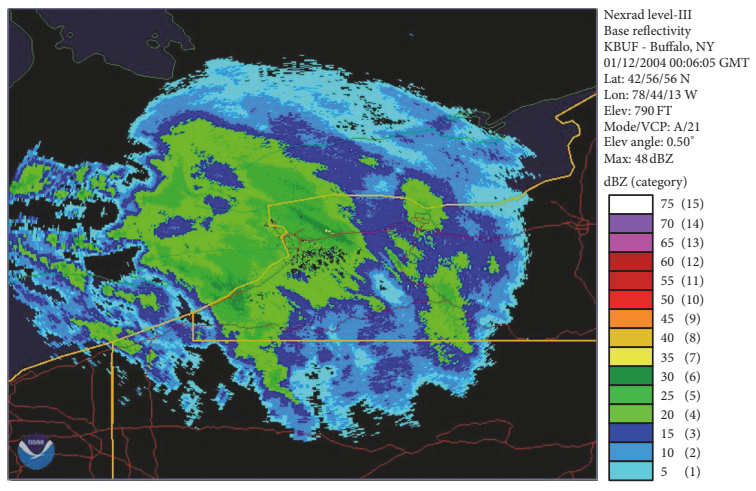

(c) As in Figure 14(a), except valid at 0006 UTC 12 January 2004

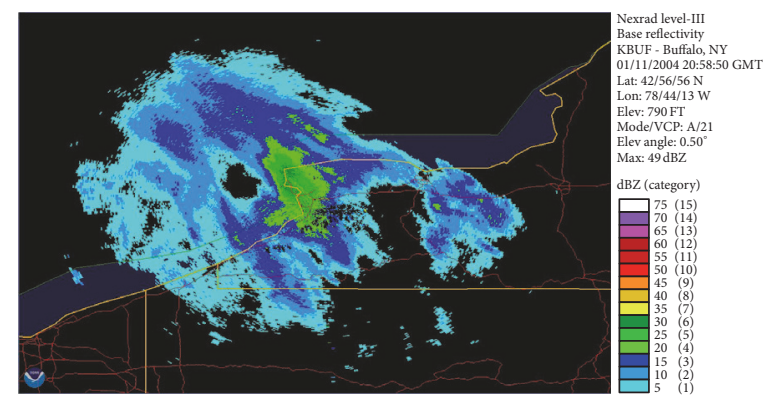

(b) As in Figure 14(a), except valid at 2058 UTC 11 January 2004

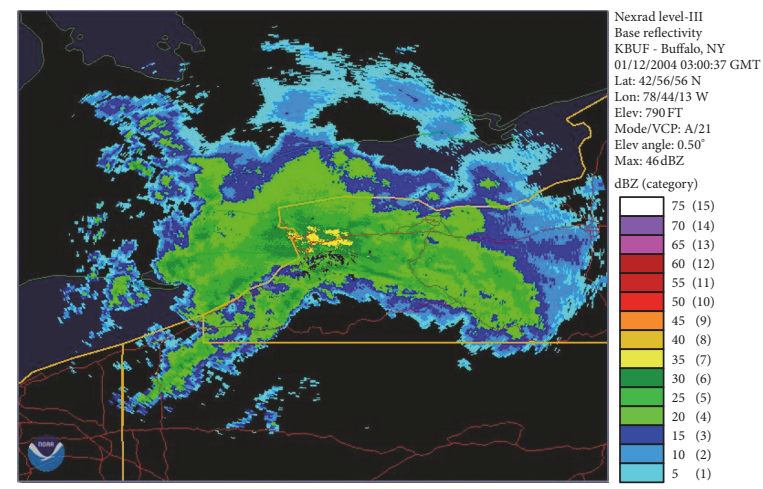

(d) As in Figure 14(a), except valid at 0300 UTC 12 January 2004

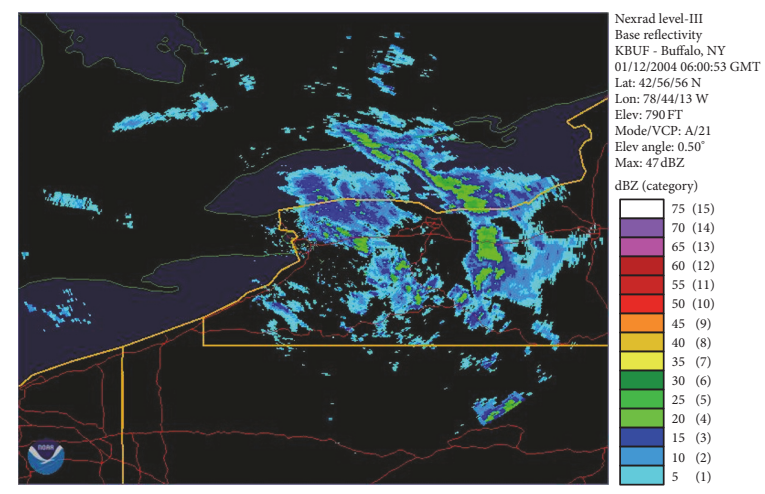

(e) As in Figure 14(a), except valid at 0600 UTC 12 January 2004

Figure 14

indicates generally light precipitation falling over the western end of Lake Ontario and the adjacent south shore, but nothing in or around Buffalo. Radar returns were also present between Rochester and Syracuse, well to the east of the radar's location. The 2058 UTC image (Figure 14(b)) has light to moderate snowfall over western New York, with maximum reflectivity values on the order of $30 \mathrm{dBZ}$ over the Niagara Peninsula and western Lake Erie.

The 0006 UTC 12 January 2004 reflectivity image (Figure 14(c)) shows a general expansion of the heavier snowfall region across western New York and the nearby lakes, with a very small but distinct 35-dBZ maximum just north of the New York State Thruway east of Buffalo. Three hours later, at the height of the storm, KBUF radar indicated a well-defined snowband across the Niagara Peninsula extending eastward through western and central New York (Figure 14(d)). Reflectivity of at least $35 \mathrm{dBZ}$ was present over the Buffalo metropolitan area. By 0600 UTC (Figure 14(e)), the synoptically organized snowfall over the region appeared to be finished, with some lake-enhanced remnant precipitation over the area.

\section{Summary and Conclusions}

A clipper-type snowfall event occurred in western New York state during the evening and early morning hours of 11-12 January 2004, and in its wake $27 \mathrm{~cm}$ (11 in.) of snow fell over parts of the area. While this region is most assuredly 
used to prodigious snowfall, so much snow in such a short period of time from a fast-moving synoptic system was most unusual. Reports of thundersnow are not uncommon for this region, but generally such events accompany vigorous Type I lake-effect snowbands (Moore and Orville [39]; Niziol et al. [40]). As a result, local forecasters were caught somewhat by surprise regarding the locally intense nature of the snowfall in this event, in spite of their wealth of accumulated knowledge and experience in heavy snow forecasting.

Postmortem analysis of this event reveals that the likely culprit of this event was the interaction of two upper-level jet streaks as they propagated over the area during a roughly $12-\mathrm{h}$ period, along with localized convective instability that, while modest, was sufficient to yield charge separation. Trajectory analysis revealed that most air parcels in the lower and midtroposphere did not originate over moisture-rich areas; in addition, it appears that while the local Great Lakes might have provided some influence, the bulk of the heavy precipitation was due primarily to locally strong UVM via ULJ coupling in the presence of elevated convective instability. The divergent regions of the two jet streaks worked in concert over the lower Great Lakes region at the height of the storm, resulting in enhanced upward vertical motion and moisture transport, and ultimately snowfall totals not typically associated with fast-moving synoptic-scale disturbances. The 24-h liquid precipitation ending at 1200 UTC 12 January 2004 was $16.5 \mathrm{~mm}$ ( $0.65 \mathrm{in}$.), with a snow-liquid ratio of approximately $15: 1$, which is close to the climatological normal established by Baxter et al. [41].

Alberta clippers are most assuredly a consequence of a combination of meteorology and geography, forming in northwesterly flow regimes. Such cold-season airflow patterns are common around the world, often resulting in the development of significant snowbands in the Great Lakes region of the United States (e.g., Mulholland et al. [42]), the Gulf of Finland (e.g., Savijärvi [43]), and the Sea of Japan (e.g., Ueda et al. [44]), as well as the English Channel and Irish Sea (e.g., Norris et al. [45]). The difference in this case to these other examples is that while the significant snowfall occurred over the lower Great Lakes region of the United States, Lake Erie appeared to be of little consequence in the generation of the localized heavy snowfall amounts.

The analysis performed here obviously has the benefit of hindsight and access to finescale data without the typical demands and time pressures of an operational forecaster. While the period of interaction was brief and the affected area somewhat limited (albeit densely populated), the operational availability of short-term forecast data such as the High Resolution Rapid Refresh model (HRRR; Benjamin et al. [46]) should lead to better anticipation of mesoscale influences on synoptic-scale disturbances and their consequences.

\section{Disclosure}

Any opinions, findings, conclusions, or recommendations expressed herein are those of the authors and do not necessarily reflect the views of NSF.

\section{Conflicts of Interest}

The authors declare that they have no conflicts of interest.

\section{Acknowledgments}

The authors wish to thank Mr. Thomas McDermott of the College at Brockport for obtaining crucial data for this project. Special thanks are due to Dr. Louis Uccellini for his invaluable comments on an earlier version of this manuscript. This work was supported in part by the United States National Science Foundation (NSF), Award AGS-1258358.

\section{References}

[1] H. B. Bluestein, Synoptic-Dynamic Meteorology in Midlatitudes: Volume II: Observations and Theory of Weather Systems, Oxford University Press, New York, NY, USA, 1993.

[2] B. C. Thomas and J. E. Martin, "A synoptic climatology and composite analysis of the Alberta clipper," Weather and Forecasting, vol. 22, no. 2, pp. 315-333, 2007.

[3] T. S. Glickman, Glossary of Meteorology, American Meteorological Society, Boston, MA, USA, 2nd edition, 2000.

[4] T. A. Hutchinson, "An analysis of NMC's Nested Grid Model forecasts of Alberta clippers," Weather and Forecasting, vol. 10, no. 3, pp. 632-641, 1995.

[5] S. Petterssen, Weather Analysis and Forecasting, vol. 1, McGrawHill, New York, NY, USA, 1956.

[6] C. H. Reitan, "Frequencies of cyclones and cyclogenesis for North America, 1951-1970," Monthly Weather Review, vol. 102, no. 12 , pp. 861-868, 1974.

[7] K. M. Zishka and P. J. Smith, "The climatology of cyclones and anticyclones over North America and surrounding ocean environs for January and July 1950-77," Monthly Weather Review, vol. 108, no. 4, pp. 387-401, 1980.

[8] R. J. Murray and I. Simmonds, "Responses of climate and cyclones to reductions in Arctic winter sea ice," Journal of Geophysical Research: Atmospheres, vol. 100, no. 3, pp. 47914806, 1995.

[9] B. J. Hoskins and K. I. Hodges, "New perspectives on the Northern Hemisphere winter storm tracks," Journal of the Atmospheric Sciences, vol. 59, no. 6, pp. 1041-1061, 2002.

[10] I. Simmonds and K. Keay, "Surface fluxes of momentum and mechanical energy over the North Pacific and North Atlantic Oceans," Meteorology and Atmospheric Physics, vol. 80, no. 1-4, pp. 1-18, 2002.

[11] U. Ulbrich, G. Leckebusch, and J. Grieger, "Are greenhouse gas signals of Northern Hemisphere winter extra-tropical cyclone activity dependent on the identification and tracking methodology?" Meteorologische Zeitschrift, vol. 22, pp. 61-68, 2013.

[12] J. Ward, "The use of atmospheric analogues to predict Alberta Clipper storm trajectories in a changing global climate," Applied Geography, vol. 60, pp. 274-279, 2015.

[13] R. W. Harms, "Snow forecasting for southwestern Wisconsin," Weatherwise, vol. 26, no. 12, pp. 250-255, 1973.

[14] S. K. Beckman, "Use of enhanced IR/visible satellite imagery to determine heavy snow areas," Monthly Weather Review, vol. 115, no. 9, pp. 2060-2087, 1987.

[15] P. G. Cinzani and S. A. Changnon Jr., "A case study: 1980's surprise long-track snowstorm," Weatherwise, vol. 34, no. 2, pp. 74-76, 1981. 
[16] S. R. Silberberg, "The role of mesoscale features in a wintertime Great Lakes cyclone," Weather and Forecasting, vol. 5, no. 1, pp. 89-114, 1990.

[17] J. R. Angel and S. A. Isard, "An observational study of the influence of the Great Lakes on the speed and intensity of passing cyclones," Monthly Weather Review, vol. 125, no. 9, pp. 2228-2237, 1997.

[18] W. A. Gallus Jr. and J. F. Bresch, "An intense small-scale wintertime vortex in the midwest United States," Monthly Weather Review, vol. 125, no. 11, pp. 2787-2807, 1997.

[19] L. W. Uccellini, "Operational diagnostic applications of isentropic analysis," National. Weather Digest, vol. 1, no. 1, pp. 4-12, 1976.

[20] L. W. Uccellini and P. J. Kocin, "The interaction of jet streak circulations during heavy snow events along the East Coast of the United States," Weather and Forecasting, vol. 2, no. 4, pp. 289-308, 1987.

[21] G. J. Hakim and L. W. Uccellini, "Diagnosing coupled jetstreak circulations for a northern Plains snow band from the operational Nested-Grid Model," Weather and Forecasting, vol. 7, no. 1, pp. 26-48, 1992.

[22] T. W. Funk and J. T. Moore, "Vertical motion forcing mechanisms responsible for the production of a mesoscale very heavy snow band across northern Kentucky," in Postprints, 4th National Winter Weather Workshop. NOAA Tech. Memo. NWS CR-112, vol. 19, pp. 1-11, 1996.

[23] J. S. Kastman, L. D. Mccoy, P. S. Market, and N. I. Fox, "An example of synergistic coupling of upper- and lower-level jets associated with flash flooding," Meteorological Applications, vol. 24, no. 2, pp. 206-210, 2017.

[24] T. L. Black, "The new NMC mesoscale Eta model: Description and forecast examples," Weather and Forecasting, vol. 9, no. 2, pp. 265-278, 1994.

[25] F. Mesinger, K. Veljovic, S. C. Chou, J. Gomes, and A. Lyra, “The Eta model: Design, use, and added value," in Topics of Climate Modeling, T. T. Hromadka and P. Rao, Eds., pp. 137-156, InTech, 2016.

[26] S. G. Benjamin, D. Dévényi, S. S. Weygandt et al., "An hourly assimilation-forecast cycle: the RUC," Monthly Weather Review, vol. 132, no. 2, pp. 495-518, 2004.

[27] S. E. Koch, M. desJardins, and P. J. Kocin, "An interactive Barnes objective map analysis scheme for use with satellite and conventional data," Journal of Climate and Applied Meteorology, vol. 22, no. 9, pp. 1487-1503, 1983.

[28] A. F. Stein, R. R. Draxler, G. D. Rolph, B. J. B. Stunder, M. D. Cohen, and F. Ngan, "NOAA's HYSPLIT atmospheric transport and dispersion modeling system," Bulletin of the American Meteorological Society, vol. 96, no. 12, pp. 2059-2077, 2015.

[29] F. Mesinger, G. DiMego, E. Kalnay et al., "North American regional reanalysis," Bulletin of the American Meteorological Society, vol. 87, no. 3, pp. 343-360, 2006.

[30] C. A. Doswell III, H. E. Brooks, and R. A. Maddox, "Flash flood forecasting: an ingredients-based methodology," Weather and Forecasting, vol. 11, no. 4, pp. 560-581, 1996.

[31] D. R. Durran and L. W. Snellman, "The diagnosis of synopticscale vertical motion in an operational environment," Weather and Forecasting, vol. 2, no. 1, pp. 17-31, 1987.

[32] D. Billingsley, "Review of QG theory-Part II: The omega equation," National Weather Digest, vol. 21, no. 2, pp. 43-51, 1997.

[33] D. Billingsley, "Review of QG theory-Part III: A different approach," National Weather Digest, vol. 22, no. 3, pp. 3-10, 1998.
[34] S. M. Rochette, C. M. Gravelle, and T. A. Niziol, "Cold-season coupled upper-level jet streaks in the Northeastern U. S. Part I: weak dynamic cases," in Poster Session, National Weather Association 31st Annual Meeting, Cleveland, OH, USA, 2006.

[35] NOAA, "Storm Prediction Center Sounding Climatology Page," http://www.spc.noaa.gov/exper/soundingclimo/.

[36] NOAA, "NCEP/NCAR Reanalysis 1: Surface flux," https://www .esrl.noaa.gov/psd/data/gridded/data.ncep.reanalysis.surfaceflux.html.

[37] P. S. Market, A. M. Oravetz, D. Gaede et al., "Proximity soundings of thundersnow in the central United States," Journal of Geophysical Research, vol. 111, no. D19, 2006.

[38] W. C. Skamarock and J. B. Klemp, "A time-split nonhydrostatic atmospheric model for weather research and forecasting applications," Journal of Computational Physics, vol. 227, no. 7, pp. 3465-3485, 2008.

[39] P. K. Moore and R. E. Orville, "Lightning characteristics in lakeeffect thunderstorms," Monthly Weather Review, vol. 118, no. 9, pp. 1767-1782, 1990.

[40] T. A. Niziol, W. R. Snyder, and J. S. Waldstreicher, "Winter weather forecasting throughout the eastern United States. Part IV: Lake effect snow," Weather and Forecasting, vol. 10, no. 1, pp. 61-77, 1995.

[41] M. A. Baxter, C. E. Graves, and J. T. Moore, "The use of climatology to construct a physically based method for diagnosing snow to liquid ratio," National Weather Digest, vol. 30, no. 1, pp. 29-44, 2006.

[42] J. P. Mulholland, J. Frame, S. W. Nesbitt, S. M. Steiger, K. A. Kosiba, and J. Wurman, "Observations of misovortices within a long-lake-axis-parallel lake-effect snowband during the OWLeS Project," Monthly Weather Review, vol. 145, no. 8, pp. 3265-3291, 2017.

[43] H. I. Savijärvi, "Cold air outbreaks over high-latitude sea gulfs," Tellus Series A: Dynamic Meteorology and Oceanography, vol. 64, no. 1, Article ID 12244, 2012.

[44] H. Ueda, A. Kibe, M. Saitoh, and T. Inoue, "Snowfall variations in Japan and its linkage with tropical forcing," International Journal of Climatology, vol. 35, no. 6, pp. 991-998, 2015.

[45] J. Norris, G. Vaughan, and D. M. Schultz, "Snowbands over the English Channel and Irish Sea during cold-air outbreaks," Quarterly Journal of the Royal Meteorological Society, vol. 139, no. 676, pp. 1747-1761, 2013.

[46] S. G. Benjamin, S. S. Weygandt, J. M. Brown et al., "A North American hourly assimilation and model forecast cycle: The rapid refresh," Monthly Weather Review, vol. 144, no. 4, pp. 1669-1694, 2016. 

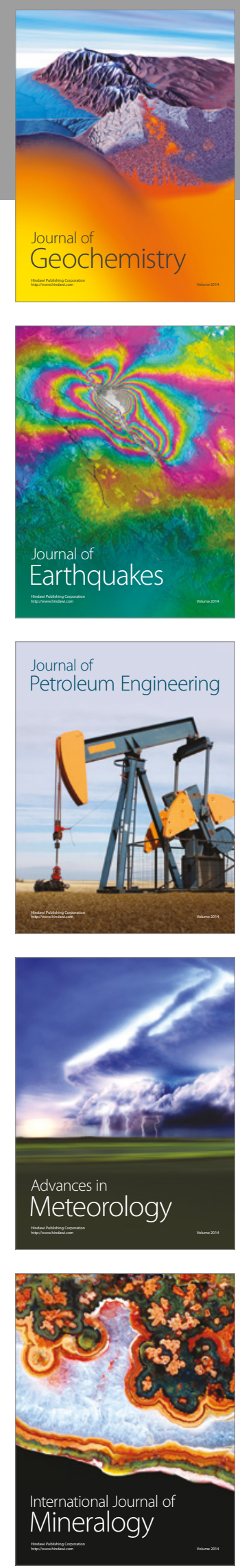
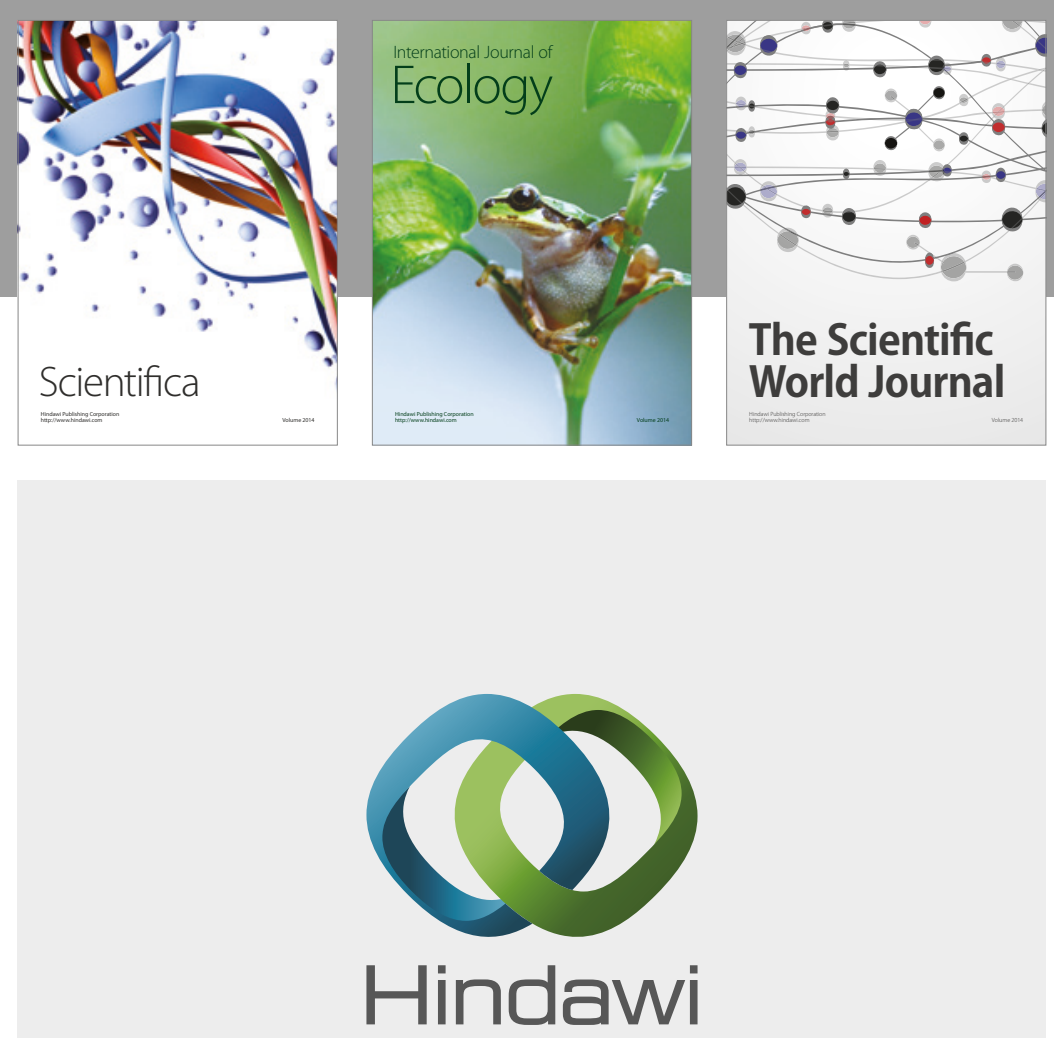

Submit your manuscripts at

https://www.hindawi.com
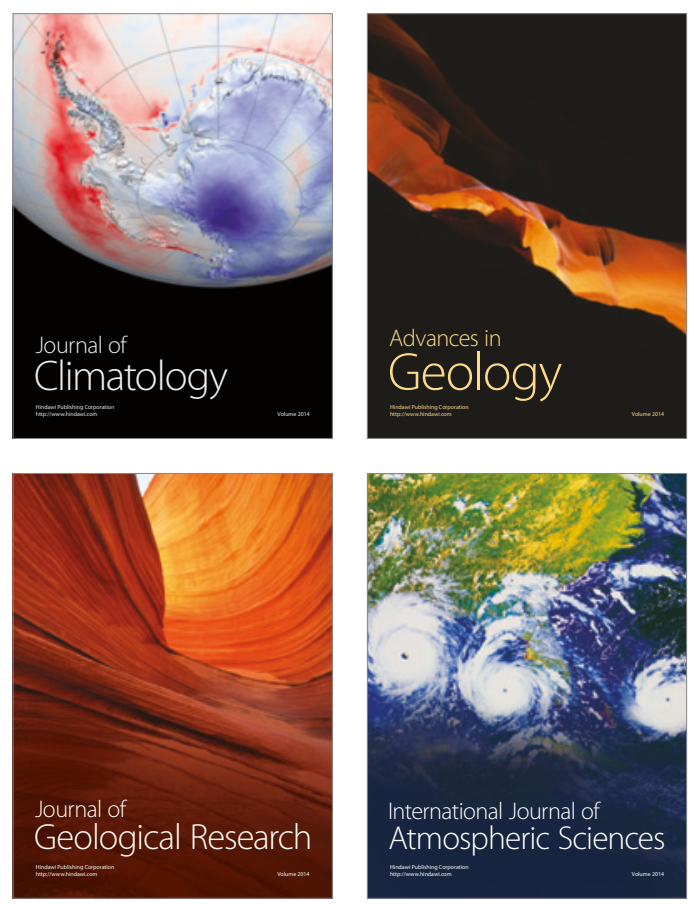

The Scientific

World Journal
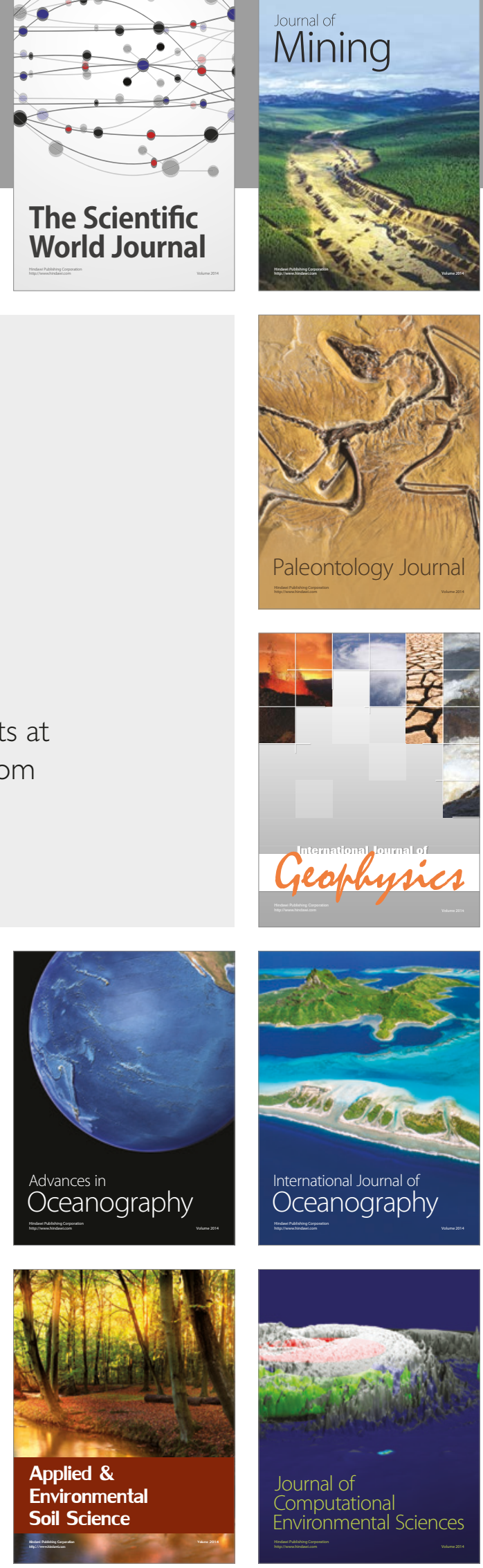